\title{
Store-0perated $\mathrm{Ca}^{2+}$ Entry in Sensory Neurons: Functional Role and the Effect of Painful Nerve Injury
}

\author{
Geza Gemes, ${ }^{1,2}$ Madhavi Latha Yadav Bangaru, ${ }^{1}$ Hsiang-En Wu, ${ }^{1}$ Qingbo Tang, ${ }^{1}$ Dorothee Weihrauch, ${ }^{1}$ \\ Andrew S. Koopmeiners, ${ }^{1}$ James M. Cruikshank, ${ }^{1}$ Wai-Meng Kwok, ${ }^{1}$ and Quinn H. Hogan ${ }^{1,3}$ \\ ${ }^{1}$ Department of Anesthesiology, Medical College of Wisconsin, Milwaukee, Wisconsin 53226, ${ }^{2}$ Department of Anesthesiology and Intensive Care Medicine, \\ Medical University of Graz, 8036 Graz, Austria, and ${ }^{3}$ Zablocki Veterans Affairs Medical Center, Milwaukee, Wisconsin 53295
}

Painful nerve injury disrupts levels of cytoplasmic and stored $\mathrm{Ca}^{2+}$ in sensory neurons. Since influx of $\mathrm{Ca}^{2+}$ may occur through store-operated $\mathrm{Ca}^{2+}$ entry (SOCE) as well as voltage- and ligand-activated pathways, we sought confirmation of SOCE in sensory neurons from adult rats and examined whether dysfunction of SOCE is a possible pathogenic mechanism. Dorsal root ganglion neurons displayed a fall in resting cytoplasmic $\mathrm{Ca}^{2+}$ concentration when bath $\mathrm{Ca}^{2+}$ was withdrawn, and a subsequent elevation of cytoplasmic $\mathrm{Ca}^{2+}$ concentration $\left(40 \pm 5 \mathrm{nM}\right.$ ) when $\mathrm{Ca}^{2+}$ was reintroduced, which was amplified by store depletion with thapsigargin (1 $\left.\mu \mathrm{M}\right)$, and was

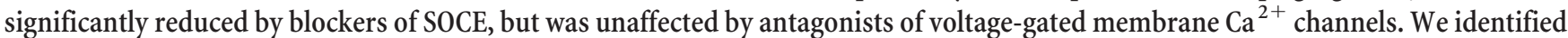
the underlying inwardly rectifying $\mathrm{Ca}^{2+}$-dependent $I_{\mathrm{CRAC}}\left(\mathrm{Ca}^{2+}\right.$ release activated current), as well as a large thapsigargin-sensitive inward current activated by withdrawal of bath divalent cations, representing SOCE. Molecular components of SOCE, specifically STIM1 and Orail, were confirmed in sensory neurons at both the transcript and protein levels. Axonal injury by spinal nerve ligation (SNL) elevated SOCE and $I_{\mathrm{CRAC}}$. However, SOCE was comparable in injured and control neurons when stores were maximally depleted by thapsigargin, and STIM1 and Orail levels were not altered by SNL, showing that upregulation of SOCE after SNL is driven by store depletion. Blockade of SOCE increased neuronal excitability in control and injured neurons, whereas injured neurons showed particular dependence on SOCE for maintaining levels of cytoplasmic and stored $\mathrm{Ca}^{2+}$, which indicates a compensatory role for SOCE after injury.

\section{Introduction}

The concentration of cytoplasmic $\mathrm{Ca}^{2+}\left(\left[\mathrm{Ca}^{2+}\right]_{\mathrm{c}}\right)$ is the dominant regulator of numerous neuronal functions, including differentiation, excitation, synaptic transmission, and apoptosis (Ghosh and Greenberg, 1995; Paschen, 2001). Sensory neurons possess an array of plasmalemmal channels that admit $\mathrm{Ca}^{2+}$ in response to depolarization, binding of ligands, heat, cold, depressed $\mathrm{pH}$, and mechanical distortion. $\mathrm{Ca}^{2+}$ signals initiated by these high-conductance channels are modulated by concurrent extrusion of $\mathrm{Ca}^{2+}$ from the neuron, as well as bidirectional exchange of $\mathrm{Ca}^{2+}$ between the neuronal cytoplasm and stores in endoplasmic reticulum (ER) and mitochondria. Inflammation and injury of sensory neurons disrupts this ensemble of interacting processes (Fuchs et al., 2007; Lu and Gold, 2008; Gemes et al., 2009; Rigaud et al., 2009).

There is expanding recognition in diverse cell types of $\mathrm{Ca}^{2+}$ entry through low-conductance plasmalemmal channels that are regulated by the level of $\mathrm{Ca}^{2+}$ stored in the ER, a process known as store-operated $\mathrm{Ca}^{2+}$ entry (SOCE). This pathway and its underlying $\mathrm{Ca}^{2+}$-release-activated current, $I_{\mathrm{CRAC}}$, are well defined

Received Sept. 26, 2010; revised Dec. 19, 2010; accepted Dec. 29, 2010.

This work was supported by National Institutes of Health Grants NS-42150 (Q.H.H.) and DA-K01 02475 (H.-E.W.).

We thank Dr. Ranjan K. Dash (Department of Physiology, Biotechnology, and Bioengineering Center, Medical College of Wisconsin) for expert assistance.

Correspondence should be addressed to Dr. Quinn H. Hogan, Department of Anesthesiology, Medical College of Wisconsin, 8701 Watertown Plank Road, Milwaukee, WI 53226. E-mail: qhogan@mcw.edu.

DOI:10.1523/JNEUROSCI.5053-10.2011

Copyright $\odot 2011$ the authors $\quad 0270-6474 / 11 / 313536-14 \$ 15.00 / 0$ in nonexcitable cells (Hofer et al., 1998; Braun et al., 2001; Mercer et al., 2006), for which SOCE is the dominant route of $\mathrm{Ca}^{2+}$ influx. Recent identification of stromal interaction molecule 1 (STIM1) as the ER $\mathrm{Ca}^{2+}$ sensor that regulates SOCE (Stathopulos et al., 2006), and Orail as a pore-forming subunit conducting $I_{\text {CRAC }}$ (Mercer et al., 2006), has allowed detailed characterization of SOCE in cells expressing these collaborating elements. Such studies have established cardinal features of SOCE, including amplification by depletion of $\mathrm{Ca}^{2+}$ stores, inward rectification of $I_{\mathrm{CRAC}}$, high inward conductance of $\mathrm{Na}^{+}$through store-operated $\mathrm{Ca}^{2+}$ channels in the absence of divalent cations (DeHaven et al., 2007), and sensitivity of SOCE to certain semiselective blockers (Putney, 2001).

A small number of studies have examined SOCE in neurons. Interference with SOCE may depress $\left[\mathrm{Ca}^{2+}\right]_{\mathrm{C}}$ and deplete sensory neuron intracellular $\mathrm{Ca}^{2+}$ stores (Usachev and Thayer, 1999), which also follows painful nerve injury (Rigaud et al., 2009). Additionally, SOCE may regulate kinase activity and synaptic transmission (Emptage et al., 2001; Cohen and Fields, 2006), providing strong motivation for expanded exploration of SOCE in sensory neurons under baseline and injured conditions. Accordingly, the present study pursues several goals. First, since previous findings that identified the basic effects of SOCE on resting $\left[\mathrm{Ca}^{2+}\right]_{\mathrm{c}}$ and $\mathrm{Ca}^{2+}$ stores in sensory neurons examined neonatal sensory neurons after prolonged culture (Usachev and Thayer, 1999), we sought to extend those findings using acutely isolated adult sensory neurons, to limit effects of prolonged culture (Scott and Edwards, 1980) and to allow comparison in pain 
models using adult animals. Second, we wanted to determine the fundamental features of SOCE in sensory neurons by directly examining $I_{\mathrm{CRAC}}$ and determining whether these neurons express the molecular components of SOCE described in other cell types. Third, since the functional role of SOCE is poorly defined in neurons, we examined the influence of SOCE on $\mathrm{Ca}^{2+}$ stores, resting $\left[\mathrm{Ca}^{2+}\right]_{\mathrm{c}}$, and excitability. Finally, to determine whether SOCE contributes to neuropathic pain, we also characterized SOCE in a model of peripheral nerve injury.

\section{Materials and Methods}

All methods and use of animals were approved by the Medical College of Wisconsin Institutional Animal Care and Use Committee.

Injury model. Male Sprague Dawley (Taconic Farms) rats weighing 160-180 g were subjected to spinal nerve ligation (SNL) in a manner derived from the original technique (Kim and Chung, 1992). Rats were anesthetized with $2 \%$ isoflurane in oxygen and the right paravertebral region was exposed. After removal of the sixth lumbar (L6) transverse process, the L5 and L6 spinal nerves were ligated with 6-0 silk suture and transected distal to the ligature. The fascia was closed with 4-0 resorbable polyglactin suture and the skin closed with staples. Control animals received anesthesia, skin incision, and stapling only. After surgery, the rats were returned to their cages and kept under normal housing conditions with access to pellet food and water ad libitum.

Sensory testing. Rats underwent sensory testing for a form of hyperalgesic behavior that we have previously documented to be associated with an aversive percept (Hogan et al., 2004; Wu et al., 2010). Briefly, on three different days between 10 and $17 \mathrm{~d}$ after surgery, right plantar skin was mechanically stimulated with a 22 gauge spinal needle with adequate pressure to indent but not penetrate the skin. Whereas control animals respond with only a brief reflexive withdrawal, rats after SNL may display a complex hyperalgesia response that incorporates sustained licking, chewing, grooming, and sustained elevation of the paw. The frequency of hyperalgesia responses was tabulated for each rat.

Neuron isolation and plating. The right L5 ganglia were rapidly harvested after isoflurane anesthesia and decapitation and were incubated in $0.01 \%$ blendzyme 2 (Roche Diagnostics) for $30 \mathrm{~min}$ followed by incubation in $0.25 \%$ trypsin (Sigma-Aldrich) and $0.125 \%$ DNase (SigmaAldrich) for $30 \mathrm{~min}$, both dissolved in DMEM/F12 with glutaMAX (Invitrogen). After exposure to $0.1 \%$ trypsin inhibitor and centrifugation, the pellet was gently triturated in culture medium containing Neural Basal Media A with B27 supplement (Invitrogen), 0.5 mm glutamine, $10 \mathrm{ng} / \mathrm{ml}$ nerve growth factor 7S (Alomone Labs), and $0.02 \mathrm{mg} / \mathrm{ml}$ gentamicin (Invitrogen). Dissociated neurons were plated onto poly-Llysine-coated glass coverslips (Deutsches Spiegelglas; Carolina Biological Supply) and maintained at $37^{\circ} \mathrm{C}$ in humidified $95 \%$ air and $5 \% \mathrm{CO}_{2}$ for $2 \mathrm{~h}$, and were studied no later than $6 \mathrm{~h}$ after harvest.

Solutions and agents. Unless otherwise specified, the bath contained Tyrode's solution (in mM: $140 \mathrm{NaCl}, 4 \mathrm{KCl}, 2 \mathrm{CaCl}_{2}, 10$ glucose, $2 \mathrm{MgCl}_{2}$, 10 HEPES, with an osmolarity of $297-300 \mathrm{mOsm}$ and $\mathrm{pH}$ 7.40). In some experiments, a $\mathrm{Ca}^{2+}$-free Tyrode's was used that contained the following (in mM): $140 \mathrm{NaCl}, 4 \mathrm{KCl}, 10$ glucose, $2 \mathrm{MgCl}_{2}, 10$ HEPES, and 0.2 EGTA.

Agents were obtained as follows: 2-aminoethyl diphenylborinate (2APB), bovine albumin, caffeine, dimethylsulfoxide (DMSO), lanthanum chloride, 1-[2-(4-methoxyphenyl)-2-[3-(4-methoxyphenyl)propoxy] ethyl]imidazole (SKF-96365), thapsigargin (TG), $N, N, N^{\prime}, N^{\prime}$-tetrakis(2-pyridylmethyl)-ethylenedidiamine (TPEN), and 7-nitroindazole (7-NI) from Sigma-Aldrich, fura-2 AM from Invitrogen, and 1-(2-trifluoromethylphenyl)imidazole (TRIM) from Alexis Biochemicals. Stock solutions of 2-APB, SKF-96365, TG, 7-NI, TRIM, and fura-2 AM were dissolved in DMSO and subsequently diluted in the relevant bath solution such that final bath concentration of DMSO was $0.2 \%$ or less, which has no effect on $\left[\mathrm{Ca}^{2+}\right]_{c}$ $(n=20)$ (data not shown). The $0.5 \mathrm{ml}$ recording chamber was constantly superfused by a gravity-driven bath flow at a rate of $3 \mathrm{ml} / \mathrm{min}$. Agents were delivered by directed microperfusion controlled by a computerized valve system through a $500-\mu \mathrm{m}$-diameter hollow quartz fiber $300 \mu \mathrm{m}$ upstream from the neurons. This flow completely displaced the bath solution, and constant flow was maintained by delivery of bath solution when specific agents were not being administered. Solution changes were achieved within $200 \mathrm{~ms}$.

Measurement of cytoplasmic $\mathrm{Ca}^{2+}$ concentration. Coverslips holding plated neurons were transferred to a room temperature $5 \mu \mathrm{M}$ solution of fura- $2 \mathrm{AM}$ that contained $2 \%$ bovine albumin to aid dispersion of the fluorophore. After $30 \mathrm{~min}$, they were washed three times with regular Tyrode's solution and left in a dark environment for deesterification for $30 \mathrm{~min}$ and then mounted onto the recording chamber. The fluorophore was excited alternately with 340 and $380 \mathrm{~nm}$ wavelength illumination (150 W xenon, Lambda DG-4; Sutter), and images were acquired at 510 $\mathrm{nm}$ using a cooled 12 bit digital camera (Coolsnap fx; Photometrics) and inverted microscope (Diaphot 200; Nikon Instruments) through a 20 or $40 \times$ Fluor oil-immersion objective. Recordings from each neuron were obtained as separate regions of interest by appropriate software (MetaFluor; Molecular Devices) at a rate of $3 \mathrm{~Hz}$. After background subtraction, the fluorescence ratio $R$ for individual neurons was determined as the intensity of emission during $340 \mathrm{~nm}$ excitation $\left(I_{340}\right)$ divided by $I_{380}$, on a pixel-by-pixel basis. The calcium concentration was then estimated by the formula $\left[\mathrm{Ca}^{2+}\right]_{\mathrm{c}}=K_{\mathrm{d}} \cdot \beta \cdot\left(R-R_{\min }\right) /\left(R_{\max }-R\right)$, where $\beta=$ $\left(I_{380 \max }\right) /\left(I_{380 \mathrm{~min}}\right)$. Values of $R_{\min }, R_{\max }$, and $\beta$ were determined by periodical in situ calibrations as described previously (Fuchs et al., 2005) and were $0.38,8.49$, and 9.54, respectively, and $224 \mathrm{~nm}$ was used as $K_{\mathrm{d}}$ (Grynkiewicz et al., 1985). Neurons were visually examined in the brightfield mode and those showing signs of lysis, crenulation, or superimposed glial cells were excluded. Similarly, only neurons with stable baseline $R$ traces were further evaluated. Traces were analyzed using Axograph X 1.1 (Axograph Scientific). Neurons were characterized by diameter as large $(>34 \mu \mathrm{m})$, which represent predominantly fastconducting non-nociceptive $A \beta$ neurons, or small $(<34 \mu \mathrm{m})$, which represent a mix of $A \beta$ neurons, slower conducting $A \delta$ nociceptive neurons, and C-type nonmyelinated nociceptive neurons (data not shown). Unless otherwise stated, small neurons were examined. Fura-2 fluorescence during $\mathrm{Sr}^{2+}$ entry represents a mix of cytoplasmic $\mathrm{Ca}^{2+}$ and $\mathrm{Sr}^{2+}$, and transients were not calibrated, but rather are reported in $R$ units.

Quantitative reverse transcriptase-PCR analysis. Total RNA was isolated from the homogenized L5 dorsal root ganglia (DRGs) of control animals, and separately from the L4 and L5 DRGs of SNL rats harvested $21 \mathrm{~d}$ after surgery, following the manufacturer's (Invitrogen) instructions using Trizol reagent (from aqueous phase). After DNase treatment, cDNA was synthesized from equal amounts of RNA using SuperScript III first-strand synthesis kit (Invitrogen). Real-time PCR analysis was performed in duplicate for each run using iQ SYBR Green supermix (Bio-Rad) and specific primers to quantify the CDNA levels of STIM1 [forward primer (FP), GTGCGCTCGTCTTGCCCTGT; reverse primer (RP), TGCGGACGGCCTCAAAGCTG) and Orail (FP, CTGGCGCAAGCTCTACTTGA; RP, AGTAACCCTGGCGGGTAGTC). The expression level of housekeeping gene Tubb5 (FP, CATGGACGAGATGGAGTTCA; RP, GAAACAAAGGGCAGTTGGAA) was used for normalization. For each sample, two interrun determinations were averaged. Statistical evaluation was performed on normalized values. Figures show fold difference in expression of STIM1 and Orail in the DRGs from SNL animals, which was calculated by comparison with that of control DRGs.

Immunoblotting. Total protein was isolated from homogenized L5 DRGs from control animals and separately from L4 and L5 DRGs of SNL rats harvested $21 \mathrm{~d}$ after surgery following manufacturer's (Invitrogen) instructions using Trizol reagent and sequential precipitation (from organic phase). Equal amounts of protein ( $20-50 \mu$ g; determined by Pierce bicinchoninic acid protein assay kit; Thermo Scientific) were separated on $4-15 \%$ SDS-PAGE gel (Bio-Rad) and transferred onto a polyvinylidene fluoride membrane. After blocking with 5\% milk in TBST (Trisbuffered saline plus $0.1 \%$ Tween 20 ), blots were sequentially probed with anti- $\beta$-Tubulin I mouse monoclonal antibody (1:20,000; Sigma-Aldrich; catalog \#T7816), anti-STIM1 rabbit polyclonal antibody (1:500; ProSci; catalog \#4119), and anti-Orail rabbit polyclonal antibody (1:1000; ProSci, catalog \#4281). Because of nonspecific bands using this antibody, Orail protein expression was examined with a second anti-Orail rabbit polyclonal antibody (1:1000; Abcam), which also showed nonspecific binding. The ProSci antibody was used for data shown here. Western blot Restore stripping buffer (Thermo Scientific) was used to strip antibodies 
from the membrane. Horseradish peroxidase-conjugated goat antirabbit and goat anti-mouse antibodies (1:2000) were used as secondary antibodies (Pierce). Enhanced chemiluminescence (GE Healthcare) was used for the detection of the protein bands. The bands obtained were quantified using NIH ImageJ program, and $\beta$-Tubulin I was used to normalize the protein loading.

Immunohistochemistry. Twenty-one days after surgery, control and injured rats were perfused with saline followed by $4 \%$ paraformaldehyde. The control L5 DRGs and L4 and L5 DRGs from SNL rats were harvested and postfixed in $4 \%$ paraformaldehyde overnight, followed by incubation in 30\% sucrose for $8 \mathrm{~h}$. Tissues were frozen in TissueTek optimal cutting temperature compound (Ted Pella). Sections ( $15 \mu \mathrm{m})$ were permeabilized with PBS plus $0.1 \%$ Triton X-100 (PBST) for 20 min, blocked with $8 \%$ normal goat serum for $2 \mathrm{~h}$, and then incubated overnight with anti-STIM1 rabbit polyclonal antibody (1:1500; ProSci). After three washes with PBST, sections were incubated with Alexa Fluor 568 goat anti-rabbit antibody (1:500; Invitrogen) for $1 \mathrm{~h}$. The sections were washed thrice with PBST and examined by confocal microscopy. The expression level of STIM1 protein was represented by the average image intensity of two sites in each cell in images that were captured using standardized camera parameters, and cell area was determined by outlining the neuronal profile.

To determine colocalization of STIM1 with the neuron-specific nuclear protein $(\mathrm{NeuN})$, sections were blocked with $8 \%$ NGS, incubated overnight with anti-STIM1 rabbit polyclonal antibody (1:1500) and antiNeuN mouse monoclonal antibody (1:500; Millipore) followed by incubation with Alexa Fluor 568 anti-rabbit IgG (1:500; Invitrogen) for STIM1 antibody and Alexa Fluor 488 goat anti-mouse IgG conjugated with (1:1000; Invitrogen) to bind NeuN antibody for $1 \mathrm{~h}$. To determine colocalization of STIM1 with glutamine synthetase, sections were blocked with $8 \%$ NGS, incubated overnight with anti-STIM1 rabbit polyclonal antibody (1:1500) followed by incubation with Alexa Fluor 568 goat anti-rabbit IgG (1:500) (Invitrogen). After three washes with PBST, the sections were incubated with anti-glutamine synthetase rabbit polyclonal antibody (1:500) (Santa Cruz Biotechnology) for $2 \mathrm{~h}$. After washes, sections were incubated with Alexa Fluor 488 goat anti-rabbit IgG (1:1000; Invitrogen) for $1 \mathrm{~h}$. Sections were washed three times with PBST and examined by confocal microscopy.

Intracellular electrophysiological recording. Intracellular recordings were performed with microelectrodes fashioned from borosilicate glass ( $1 \mathrm{~mm}$ outer diameter, $0.5 \mathrm{~mm}$ inner diameter; with Omega fiber; FHC) using a P-97 programmable micropipette puller (Sutter). Pipettes were filled with $2 \mathrm{M}$ potassium acetate, which was buffered with $10 \mathrm{mM}$ HEPES, with a resulting resistance of 70-100 $\mathrm{M} \Omega$. For recording from dissociated neurons, coverslips carrying the neurons were mounted onto a $500 \mu \mathrm{l}$ chamber and constantly superfused with Tyrode's solution at $3 \mathrm{ml} / \mathrm{min}$. Neurons were selected in bright-field mode on an upright microscope using a $40 \times$ water-immersion objective and impaled under direct vision with the aid of an oscillating current to the recording electrode. Membrane potential was recorded using an active bridge amplifier (Axoclamp 2B; Molecular Devices). Voltage recordings were filtered at $10 \mathrm{kHz}$ and then digitized at $40 \mathrm{kHz}$ (Digidata 1322A; Molecular Devices; and Axograph X 1.1) for data acquisition and analysis. Alternatively, for recording from neuronal somata in intact DRGs, ganglia were perfused with a bath solution (in mM: $128 \mathrm{NaCl}, 3.5 \mathrm{KCl}, 1.2 \mathrm{MgCl}_{2}, 2.3 \mathrm{CaCl}_{2}, 1.2$ $\mathrm{NaH}_{2} \mathrm{PO}_{4}, 24.0 \mathrm{NaHCO}_{3}, 11.0$ glucose) bubbled by $5 \% \mathrm{CO}_{2}$ and $95 \% \mathrm{O}_{2}$ to maintain a $\mathrm{pH}$ of 7 . Neurons were impaled using differential interference contrast imaging with infrared illumination. Voltage error was minimized using a switching amplifier (Axoclamp 2B) operating in discontinuous current-clamp mode with a switching rate of $2 \mathrm{kHz}$, while monitoring for complete settling of electrode potential between sampling. Voltage recordings were filtered at $1 \mathrm{kHz}$. Recordings were not started until resting membrane potential had stabilized and resting membrane potential (RMP) was less than $-45 \mathrm{mV}$ (typically within $2 \mathrm{~min}$ ). Somatic action potentials (APs) were generated by direct membrane depolarization with current injection through the recording electrode. The rheobase current was determined as the minimal depolarization adequate to produce an AP, and the resting voltage during this depolarization was considered the voltage threshold. AP duration was measured at 50\% resolution, whereas afterhyperpolarization (AHP) duration was measured at $80 \%$ resolution toward RMP. Excitability was assayed two ways. Examination of the firing pattern during depolarizing current injection (100 ms, $0.2 \mathrm{nA}$ increments) through the recording electrode allowed categorization of neurons as either repetitively firing versus those that fire only a single AP despite depolarization (accommodation). Data were included only from neurons that generated an initial AP at 10 $\mathrm{mV}$ or less, and firing behavior was evaluated during additional depolarization up to $30 \mathrm{mV}$. A second, additional analysis of repetitively firing neurons examined the slope relating the number of APs evoked at different transmembrane potentials during depolarization. This frequency gain (number of APs per millivolt) was determined as a liner fit only for neurons that showed at least three different levels of firing (number of APs) at potentials $<30 \mathrm{mV}$.

Patch-clamp electrophysiological recording. Voltage and currents were recorded in small- to medium-size neurons ( $28.8 \pm 0.4 \mu \mathrm{m} ; n=36$ ), using the whole-cell configuration of the patch-clamp technique at room temperature. Patch pipettes, ranging from 2 to $5 \mathrm{M} \Omega$ resistance, were formed from borosilicate glass (Garner Glass) and fire polished. Currents were recorded with an Axopatch 200B amplifier (Molecular Devices), filtered at $2 \mathrm{kHz}$ through a 4-pole Bessel filter, and digitized at $10 \mathrm{kHz}$ with a Digidata $1320 \mathrm{~A} / \mathrm{D}$ interface and pClamp 9 software (Molecular Devices) for storage on a personal computer. After achieving gigaohm seal and breakthrough, membrane capacitance was determined and access resistance was compensated $(60-85 \%)$. Access resistance was typically between 5 and $10 \mathrm{M} \Omega$ after breakthrough.

A modified Tyrode's solution was used for external bath solution, consisting of the following (in mM): $140 \mathrm{NaCl}, 4 \mathrm{KCl}, 2 \mathrm{CaCl}_{2}, 2 \mathrm{MgCl}_{2}$, 10 D-glucose, 10 HEPES at $\mathrm{pH}$ of 7.4 adjusted with $\mathrm{NaOH}$ and an osmolarity of $300 \mathrm{mOsm}$ adjusted with sucrose. The internal pipette solution contained the following (in $\mathrm{mM}$ ): $120 \mathrm{KCl}, 5 \mathrm{Na}$-ATP, $0.4 \mathrm{Na}$-GTP, 10 EGTA, $2.25 \mathrm{CaCl}_{2}, 5 \mathrm{MgCl}_{2}, 20$ HEPES at a $\mathrm{pH}$ of 7.2 with $\mathrm{KOH}$ and osmolarity of 296-300 mOsm. This produced a calculated $\left[\mathrm{Ca}^{2+}\right]_{\mathrm{c}}$ of 70 nм (Maxchelator program; http://maxchelator.stanford.edu). $\mathrm{A} \mathrm{Na}^{+}$free/ $\mathrm{Ca}^{2+}$-free external solution was prepared by removing the $\mathrm{NaCl}$ and $\mathrm{CaCl}_{2}$ from the modified Tyrode's solution and adding $85 \mathrm{~N}$-methyl-Dglucamine (NMDG), 0.1 EGTA, 50 tetraethylammonium (TEA), 5 4-aminopyridine.

In $\mathrm{Ca}^{2+}$ readdition experiments, $\mathrm{Na}^{+}$-free/ $\mathrm{Ca}^{2+}$-free solution was applied after the whole-cell configuration was achieved, which was then changed to an identical solution to which $\mathrm{Ca}^{2+}$ had been added to $10 \mathrm{~mm}$ final concentration (Hoth and Penner, 1992). Before and after solution changes, currents were recorded during hyperpolarization steps $(-100$ $\mathrm{mV}$ for $100 \mathrm{~ms}$ from a holding potential of $-65 \mathrm{mV}$ ) presented every $5 \mathrm{~s}$ during $\mathrm{Ca}^{2+}$ readdition. In a second protocol, currents were recorded during voltage ramps ( -100 to $+20 \mathrm{mV}$ over $100 \mathrm{~ms}$ ) that immediately followed a conditioning depolarization $(0 \mathrm{mV}$ for $500 \mathrm{~ms})$ that inactivated voltage-gated $\mathrm{Ca}^{2+}$ channels (VGCCs). Neurons were otherwise held at a potential of $-65 \mathrm{mV}$, and currents were normalized based on cell capacitance. Five traces were averaged from the baseline $\mathrm{Na}^{+}$-free/ $\mathrm{Ca}^{2+}$-free condition compared with an average of five traces obtained after steady-state responses were achieved with readded $\mathrm{Ca}^{2+}$.

Monovalent permeation experiments used a divalent-free (DVF) bath solution that was prepared by removing the $\mathrm{CaCl}_{2}$ and $\mathrm{MgCl}_{2}$ from the modified Tyrode's solution and adding $0.1 \mathrm{~mm}$ EGTA and $50 \mathrm{~mm}$ TEA (DeHaven et al., 2007). This solution was applied after the whole-cell configuration was achieved, in alternation with a solution that differed only in having $10 \mathrm{mM} \mathrm{CaCl}_{2}$. Current was recorded while neurons were continuously hyperpolarized $(-100 \mathrm{mV})$. Baseline current was determined from the initial recording $(0-5 \mathrm{~s})$ and subtracted from subsequent recording for each neuron. Responses to application of DVF solution and DVF containing $\mathrm{La}^{3+}$ or $\mathrm{Ca}^{2+}$ were determined from averaging the trace across $10 \mathrm{~s}$ once a steady-state response was achieved.

Except as described above for ramp protocols, depolarization was avoided before current recordings, to avoid $\mathrm{Ca}^{2+}$ influx that could alter the state of $\mathrm{Ca}^{2+}$ stores. External solutions were administered by bath change $(3.3 \mathrm{ml} / \mathrm{min}$; bath volume, $0.7 \mathrm{ml})$. The rate of bath change, represented by the time constant of the exponential fitted to the time course of dye washout monitored photometrically, was $\tau=21 \pm 2 \mathrm{~s}(n=$ 
7). To deplete $\mathrm{Ca}^{2+}$ stores and maximally activate $I_{\mathrm{CRAC}}$, TG $(1 \mu \mathrm{M})$ was applied for $7 \mathrm{~min}$ in the external bath after establishing whole-cell patch configuration.

Statistical analysis. Statistical analyses were performed with Statistica (StatSoft). The $t$ test or one-way ANOVA was used to detect the influence of injury group on measured parameters, except for immunoblot and quantitative reverse transcriptase-PCR (rtPCR) for which the nonparametric Kruskal-Wallis test was used. Parameters determined from intracellular recordings were analyzed by two-way ANOVA to determine the effect of injury, the effect of TRIM, and their interaction. Where main effects were observed in ANOVA, either Bonferroni's post hoc test or Tukey's test (when all possible comparisons were considered) was used to compare relevant means, and a value of $p<0.05$ was considered significant. Results are reported as average \pm SEM.

\section{Results}

A total of 139 rats was used for the study, of which 75 were control animals and 64 were subjected to SNL. The average rate of hyperalgesiatype behavioral responses was $0.6 \pm 0.3 \%$ in control animals and $41.3 \pm 2.8 \%$ in SNL animals $(p<0.001)$. All SNL animals used in this study had $>20 \%$ hyperalgesia responses to pin stimulation.

\section{SOCE is present in sensory neurons}

After a $7 \mathrm{~min}$ interval in $\mathrm{Ca}^{2+}$-free bath, which is long enough to establish a stable $\left[\mathrm{Ca}^{2+}\right]_{\mathrm{c}}(50 \pm 2 \mathrm{nM} ; n=57)$, readdition of $2 \mathrm{~mm}$ bath $\mathrm{Ca}^{2+}$ to sensory neurons initiated $\mathrm{Ca}^{2+}$ influx and resulted in a rise in $\left[\mathrm{Ca}^{2+}\right]_{\mathrm{c}}$ (Fig. $1 A$ ) to levels that exceeded the original baseline in all neurons (baseline, $73 \pm 4 \mathrm{~nm}$; readdition, $100 \pm 6$ $\mathrm{nm} ; n=37 ; p<0.001$ ). This suggests a regulatory process driven by a signal that originates in a site other than the cytoplasm. Extension of the duration of $\mathrm{Ca}^{2+}$ deprivation to 30 min before $\mathrm{Ca}^{2+}$ readdition resulted in transients with amplitudes that did not differ from those after $7 \mathrm{~min}$ in $\mathrm{Ca}^{2+}$-free bath (Fig. $1 A, B$ ). Sensory neurons are a heterogeneous population and include nociceptors that characteristically respond to capsaicin with $\mathrm{Ca}^{2+}$ influx through transient receptor potential vanilloid 1 (TRPV1) receptors (Caterina et al., 1997). The $\mathrm{Ca}^{2+}$ readdition transient amplitude in neurons that were subsequently shown to be sensitive to $10 \mathrm{~nm}$ capsaicin did not differ from those that were unresponsive to capsaicin (Fig. $1 B$ ). Large soma diameter typically characterizes fast-conducting neurons that respond to lowthreshold mechanical stimuli (Waddell and Lawson, 1990). There was no difference in $\mathrm{Ca}^{2+}$ readdition transient amplitude between large-diameter $(39 \pm 1 \mu \mathrm{m})$ and small-diameter $(27 \pm 1$ $\mu \mathrm{m})$ neurons (Fig. $1 B$ ).

A cardinal feature of SOCE is its sensitivity to the level of intracellular $\mathrm{Ca}^{2+}$ stores. We therefore tested whether the $\mathrm{Ca}^{2+}$ readdition transient is amplified by complete depletion of ER $\mathrm{Ca}^{2+}$ stores achieved through exposure of neurons to the sarcoendoplasmic $\mathrm{Ca}^{2+}$-ATPase (SERCA) inhibitor TG. By leaving the constitutive leak of $\mathrm{Ca}^{2+}$ from the ER unopposed, TG itself causes a $\left[\mathrm{Ca}^{2+}\right]_{\mathrm{c}}$ elevation that resolves within 5-7 min in $\mathrm{Ca}^{2+}$ free bath (see Fig. $3 A$ ). Application of bath $\mathrm{Ca}^{2+}$ to neurons that had been exposed to TG ( $1 \mu \mathrm{M} ; 7 \mathrm{~min})$ produced $\mathrm{Ca}^{2+}$ transients with amplitudes that were greater than those in other neurons without TG (Fig. $1 B)(p<0.01$ vs control neurons). Although the amplitude of the $\mathrm{Ca}^{2+}$ readdition transient is a commonly accepted measure of SOCE (Usachev and Thayer, 1999; Mercer et al., 2006), it is possible that competing processes that extrude $\mathrm{Ca}^{2+}$ from the neuron influence the level of the steady state that underlies the $\left[\mathrm{Ca}^{2+}\right]_{c}$ peak. Accordingly, we also examined the initial slope determined from the differentiated $\left[\mathrm{Ca}^{2+}\right]_{\mathrm{c}}$ trace, which may provide a more direct and valid measure of the rate of $\mathrm{Ca}^{2+}$ influx during bath readdition (Glitsch et al., 2002). By this
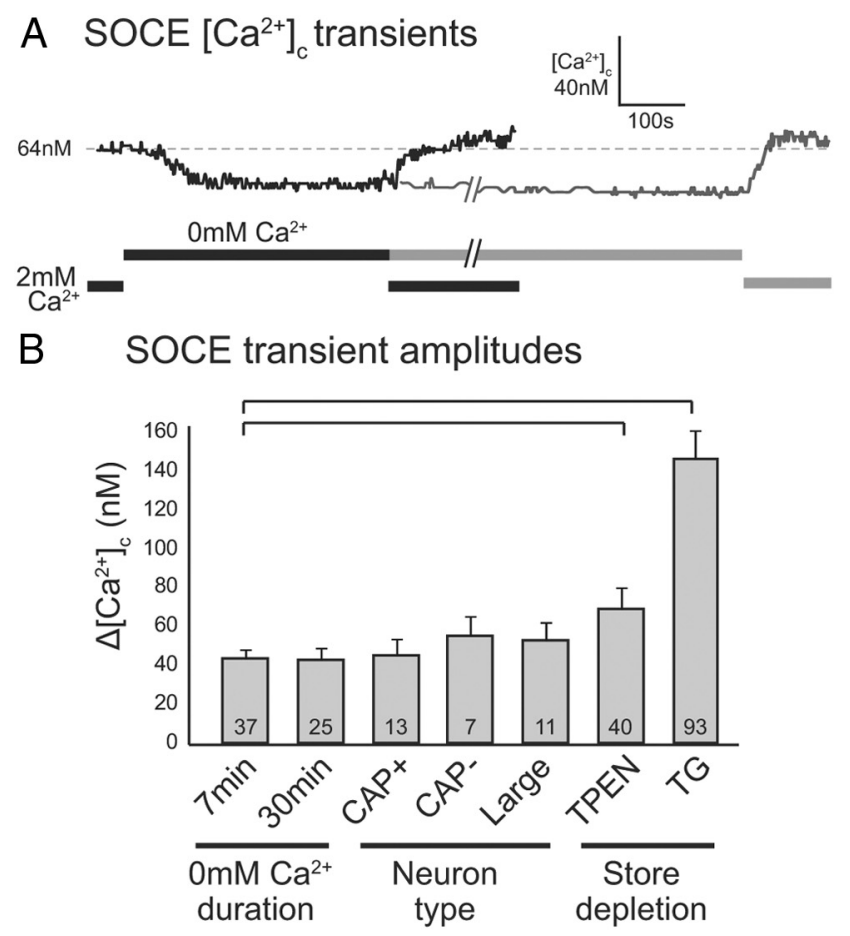

\section{Thapsigargin amplification}

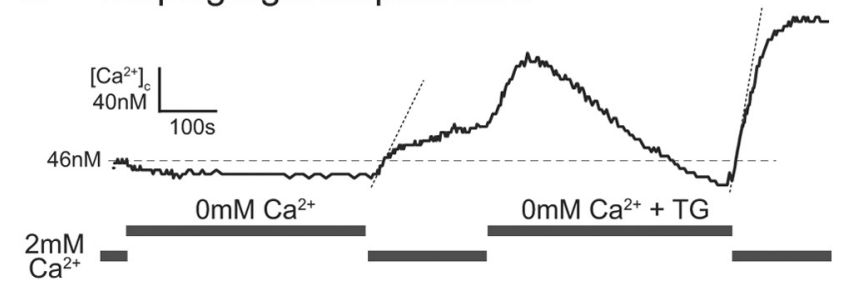

Figure 1. Manipulation of SOCE by withdrawal of $\mathrm{Ca}^{2+}$ from the bathing solution and the readdition of $\mathrm{Ca}^{2+} . A, \mathrm{Ca}^{2+}$ withdrawal reduces resting $\left[\mathrm{Ca}^{2+}\right]_{\mathrm{C}^{\prime}}$ which is mostly complete within $\sim 3 \mathrm{~min}$. Withdrawal for $30 \mathrm{~min}$ (gray trace, $32-\mu \mathrm{m}$-diameter neuron) depresses $\left[\mathrm{Ca}^{2+}\right]_{\mathrm{c}}$ only slightly more than a $7 \mathrm{~min}$ withdrawal in a different neuron (dark trace, $30 \mu \mathrm{m}$ ). Readdition of $\mathrm{Ca}^{2+}$ to the bath causes elevation of $\left[\mathrm{Ca}^{2+}\right]_{c}$ to a level higher than the original baseline (dashed line). $\boldsymbol{B}$, Amplitudes of the $\left[\mathrm{Ca}^{2+}\right]_{\mathrm{C}}$ transients induced by readdition of $\mathrm{Ca}^{2+}$ to the bath in separate groups of neurons. Unless otherwise indicated, neurons are small $(<34$ $\mu \mathrm{m}$ diameter) and the $\mathrm{Ca}^{2+}$ withdrawal is for $7 \mathrm{~min}$. There was no difference between bath $\mathrm{Ca}^{2+}$ withdrawal for 7 min versus $30 \mathrm{~min}$. Neurons sensitive to capsaicin (10 nм; Cap +) showed the same transient amplitude as insensitive neurons ( $\mathrm{Cap}-$ ). Amplitude in large neurons ( $42 \pm 2 \mu \mathrm{m}$ diameter) did not differ from small neurons. Chelation of endoplasmic reticulum $\mathrm{Ca}^{2+}$ stores with TPEN (100 $\left.\mu \mathrm{m} ; 3 \mathrm{~min}\right)$ or depletion of $\mathrm{Ca}^{2+}$ stores with TG $(1 \mu \mathrm{m} ; 7 \mathrm{~min})$ each increased the $\mathrm{Ca}^{2+}$ readdition transient amplitude. The numbers in the bars indicate number of neurons; the brackets indicate $p<0.05$. Shown are mean \pm SEM. C, Trace (typical of $n=9$ ) showing a greater increase in $\left[\mathrm{Ca}^{2+}\right]_{\mathrm{c}}$ with $\mathrm{Ca}^{2+}$ readdition to the bath solution after exposure to TG $(1 \mu \mathrm{M})$. Additionally, the maximal rate of $\left[\mathrm{Ca}^{2+}\right]_{\mathrm{C}}$ during $\mathrm{Ca}^{2+}$ readdition, indicated by the tangential dotted lines, is greater after TG $(3.2 \mathrm{~nm} / \mathrm{s})$ than before $(1.1 \mathrm{~nm} / \mathrm{s})$.

measure, the SOCE was also greater with TG $(3.85 \pm 0.39 \mathrm{~nm} / \mathrm{s}$; $n=93)$ than without TG $(0.86 \pm 0.14 \mathrm{~nm} / \mathrm{s} ; n=35 ; p<0.001)$.

To confirm the influence of TG on SOCE, separate experiments were performed in which $\mathrm{Ca}^{2+}$ readdition transients were compared in the same neuron under baseline conditions and again after TG application (Fig. 1C). TG increased the transient amplitude $2.7 \pm 0.4$-fold compared with the transient before TG $(p=0.0001 ; n=9)$. This was significantly greater amplification $(p<0.01)$ than the slight increase in the second transient $(1.2 \pm$ 0.1 -fold; $p=\mathrm{NS} ; n=24$ ) when $\mathrm{Ca}^{2+}$ readdition was repeated in the absence of TG. Measuring slopes confirmed that TG increased the $\mathrm{Ca}^{2+}$ influx rate $3.3 \pm 1.1$-fold compared with base- 
line (Fig. 1C) $(p<0.05 ; n=9)$, whereas the amplification during repeat $\mathrm{Ca}^{2+}$ readdition without TG $(1.4 \pm 0.1$-fold; $p<$ $0.01 ; n=23)$ was significantly less $(p<$ $0.001)$.

Chelation of $\mathrm{ER} \mathrm{Ca}^{2+}$ stores provides an alternative method for testing the influence of $\mathrm{Ca}^{2+}$ stores on $\mathrm{Ca}^{2+}$ influx. TPEN passes freely through membranes and only binds $\mathrm{Ca}^{2+}$ at micromolar concentration, thereby having a selective effect on stored $\mathrm{Ca}^{2+}$. In investigations of other cell types, TPEN depresses free $\mathrm{Ca}^{2+}$ concentration in ER stores within $10 \mathrm{~s}$ of application, without an effect on cytoplasmic $\mathrm{Ca}^{2+}$ levels (Hofer et al., 1998). $\mathrm{Ca}^{2+}$ readdition to sensory neurons incubated in TPEN (100 $\mu \mathrm{M} ; 3 \mathrm{~min})$ produced transient amplitudes that were on average 1.7 -fold greater $(p<0.05)$ than those in other neurons incubated in $\mathrm{Ca}^{2+}$-free bath $(7 \mathrm{~min})$ without the chelator (Fig. $\left.1 \mathrm{~B}\right)$. Compared with TPEN, TG may have a relatively greater effect on $\left[\mathrm{Ca}^{2+}\right]_{\mathrm{c}}$ rise after bath $\mathrm{Ca}^{2+}$ readdition because of its blockade of $\mathrm{Ca}^{2+}$ sequestration from the cytoplasm via SERCA. Together, the findings from depletion and chelation of $\mathrm{Ca}^{2+}$ stores reveal a $\mathrm{Ca}^{2+}$ entry process that is regulated by the state of $\mathrm{ER} \mathrm{Ca}^{2+}$ stores.

Since sensory neurons possess a variety of VGCCs, we examined the possibility that activation of these channels by membrane depolarization during $\mathrm{Ca}^{2+}$ readdition might underlie a component of the observed $\mathrm{Ca}^{2+}$ influx. Intracellular electrode recordings showed membrane potential was unchanged during withdrawal of $\mathrm{Ca}^{2+}$ from the bath and during subsequent $\mathrm{Ca}^{2+}$ readdition (Fig. $2 A, B$ ), which indicates that neither action potentials nor incremental membrane depolarization contribute to generating the $\mathrm{Ca}^{2+}$ readdition transient. It is possible nonetheless that $\mathrm{Ca}^{2+}$ may enter neurons through VGCCs that are conducting at resting membrane potential, particularly low-voltage-activated T-type $\mathrm{Ca}^{2+}$ channels (Lee et al., 1999). However, the presence of mibefradil (200 nM), a T-type VGCC blocker, did not alter the transient amplitude during $\mathrm{Ca}^{2+}$ readdition to TG-treated neurons $(1 \mu \mathrm{M} ; 7 \mathrm{~min})$ compared with a preceding $\mathrm{Ca}^{2+}$ readdition in the absence of mibefradil ( $96 \pm 14 \mathrm{~nm}$ baseline; $92 \pm 10 \mathrm{nM}$ after blockade; $p=0.63 ; n=14)$. Combined application of selective VGCC blockers (Fig. 3A) (mibefradil, nitrendipine, 10 $\mu \mathrm{M}$, for L-type current; SNX-111, $200 \mathrm{nM}$, for N-type current; $\omega$-conotoxin Aga-IVA, $200 \mathrm{nM}$, for P/Q-type current; SNX-482, $100 \mathrm{~nm}$, for R-type current) also did not alter $\mathrm{Ca}^{2+}$ readdition transient amplitudes $(94 \pm 10 \mathrm{nM}$ baseline; $135 \pm 10 \mathrm{nM}$ after blockade; $p=0.70 ; n=32$ ), which suggests that no $\mathrm{Ca}^{2+}$ enters through this pathway and confirms Usachev and Thayer's previous findings in cultured embryonic neurons.

Sensitivity to blockers of SOCE, such as low concentrations of $\mathrm{La}^{3+}$, has been used in previous studies to identify SOCE (Szikra et al., 2009). During $\mathrm{Ca}^{2+}$ readdition in TG-treated sensory neurons (Fig. 3B), we found a substantial suppression of transient amplitude by $\mathrm{La}^{3+}(10 \mu \mathrm{M})$, which eliminated $79 \pm 7 \%$ of the $\mathrm{Ca}^{2+}$ readdition transient compared with other neurons without blocker. 2-APB (100 $\mu \mathrm{M})$, another commonly used SOCE inhibitor (Bootman et al., 2002), moderately decreased the $\mathrm{Ca}^{2+}$ readdition transient amplitude in sensory neurons by $39 \pm 6 \%$. TRIM $(400 \mu \mathrm{M}$ ), which has been used to block SOCE in neurons (Tobin et al., 2006), suppressed the readdition transient by $61 \pm 5 \%$. The

\section{B Data summary} $(n=9)$

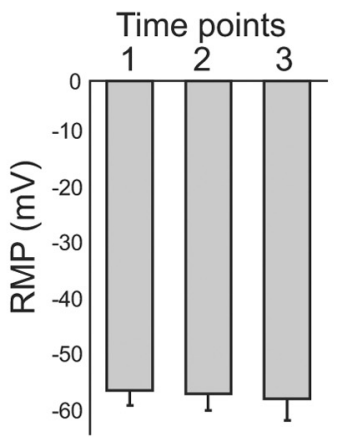

Figure 2. Membrane potential of a sensory neuron after dissociation from a dorsal root ganglion, recorded by intracellular simultaneous recording of membrane potential and $\left[\mathrm{Ca}^{2+}\right]_{c}$ from a control neuron (32 $\mu$ m diameter). $\boldsymbol{B}$, There is no difference in readdition of $\mathrm{Ca}^{2+}$ to the bath solution (time point 3). Shown are mean \pm SEM.

commonly used SOCE blocker SKF-96365 (10-50 $\mu \mathrm{M})$ did not have any significant effect on sensory neurons. ML-9, a novel SOCE blocker (Smyth et al., 2008), itself elevated $\left[\mathrm{Ca}^{2+}\right]_{\mathrm{C}}$ by $83 \pm$ $24 \mathrm{nM}(n=15)$ in neurons bathed in $\mathrm{Ca}^{2+}$-free solution, indicating release of $\mathrm{Ca}^{2+}$ from stores, and was not investigated further.

\section{$I_{\text {CRAC }}$ underlies SOCE in sensory neurons}

Direct measurement of the $\mathrm{Ca}^{2+}$ release-activated current $I_{\text {CRAC }}$ has been achieved in expression systems and in several native cell types. The exceptionally small conductance of storeoperated $\mathrm{Ca}^{2+}$ channels eliminates the option of singlechannel recording, so we used the whole-cell patch-clamp technique to identify $I_{\text {CRAC }}$.

We initially attempted to record a $\mathrm{Ca}^{2+}$-dependent inward current at the approximate natural resting potential of sensory neurons $(-65 \mathrm{mV}) \cdot \mathrm{Ca}^{2+}$ readdition produced small increases in inward current (Fig. 4A), but this approach produced inconsistent results, as has been reported previously (Liu et al., 2003). We therefore used voltage conditions that amplified the observable influence of extracellular $\mathrm{Ca}^{2+}$. During hyperpolarization steps to $-100 \mathrm{mV}$ (Fig. $4 B$ ) (Hoth and Penner, 1992), $I_{\mathrm{Ca}}$ in bath containing $10 \mathrm{mM} \mathrm{Ca}^{2+}(-1.4 \pm 0.1 \mathrm{pA} / \mathrm{pF})$ was greater than the current recorded in the same neurons in bath without $\mathrm{Ca}^{2+}$ $(-1.0 \pm 0.1 \mathrm{pA} / \mathrm{pF} ; n=5 ; p<0.001)$, confirming a $\mathrm{Ca}^{2+}$. dependent inward current in the absence of depolarization. During ramp depolarization (Parekh, 1998; DeHaven et al., 2007), comparison of currents before and after readdition of bath $\mathrm{Ca}^{2+}$ to TG-treated neurons (Fig. $4 \mathrm{C}$ ) revealed a greater current in the presence of bath $\mathrm{Ca}^{2+}(-3.1 \pm 0.8 \mathrm{pA} / \mathrm{pF}$; measured at $-80 \mathrm{mV})$ than during $\mathrm{Ca}^{2+}$-free conditions in the same neurons $(-0.8 \pm$ $0.1 \mathrm{pA} / \mathrm{pF} ; n=5 ; p<0.05)$, again demonstrating a $\mathrm{Ca}^{2+}$. dependent inward current. Inward rectification, which is a characteristic feature of $I_{\text {CRAC }}$ (Hoth and Penner, 1992), was observed in the $\mathrm{Ca}^{2+}$-dependent component of the current (Fig. $4 C$, subtracted current), supporting the identification of this current as $I_{\mathrm{CRAC}}$.

Store-operated $\mathrm{Ca}^{2+}$ channels become nonselective for $\mathrm{Ca}^{2+}$ ions in the absence of divalent cations, whereupon a high rate of $\mathrm{Na}^{+}$influx provides a more readily measurable manifestation of $I_{\text {CRAC }}$ (Hoth and Penner, 1993; DeHaven et al., 2007). Only small currents were induced on exposure of sensory neurons to DVF bath solution under baseline conditions. However, sensory neurons incubated in TG ( $1 \mu \mathrm{M}$ for $7 \mathrm{~min}$ ) showed robust $I_{\text {CRAC }}$ on 


\section{A Blockade of voltage-gated $\mathrm{Ca}^{2+}$ channels during SOCE}

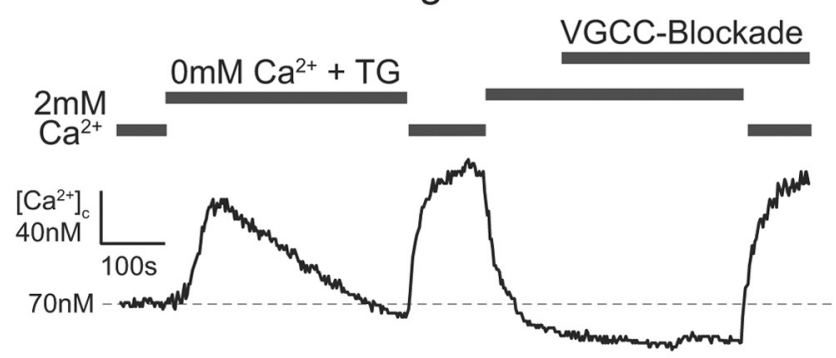

\section{B Blockers of SOCE}

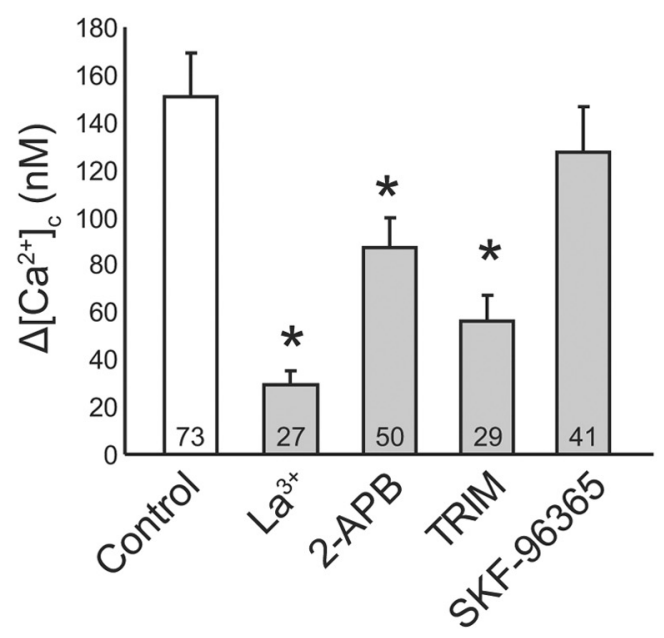

Figure 3. Effect of blockers on SOCE measured as the $\left[\mathrm{Ca}^{2+}\right]_{c}$ rise on bath $\mathrm{Ca}^{2+}$ readdition. $A$, Blockade of VGCCs with combined administration of mibefradil ( $200 \mathrm{nM}$ ) for T-type current, nitrendipine $(10 \mu \mathrm{M})$ for L-type current, SNX-111 (200 nM) for N-type current, $\omega$-conotoxin Aga-IVA (200 nм) for P/Q-type current, and SNX-482 (100 nм) for R-type current does not influence the $\left[\mathrm{Ca}^{2+}\right]_{C}$ increase on bath $\mathrm{Ca}^{2+}$ readdition in a control neuron (28 $\mu$ m diameter) treated with TG $(1 \mu \mathrm{M})$. Typical of $n=32$. B, Specific blockers of SOCE reduce the amplitude of $\left[\mathrm{Ca}^{2+}\right]_{\mathrm{c}}$ rise on bath $\mathrm{Ca}^{2+}$ readdition. La ${ }^{3+}(10 \mu \mathrm{M}), 2-\mathrm{APB}(100 \mu \mathrm{m})$, and TRIM $(400 \mu \mathrm{M})$ significantly ( $\left.{ }^{*} p<0.05\right)$ reduced transient amplitude. SKF-96365 $(10-50 \mu \mathrm{M})$ had no effect. Shown are mean \pm SEM.

exposure to DVF conditions, unlike neurons without store depletion ( $p<0.01$ for DVF with vs without TG) (Fig. $4 D, E$ ), which identifies this as a current conducted by store-operated channels. The initiation the DVF-induced inward current showed a delay $(53 \pm 7 s ; n=6)$ (Fig. 4D), despite previous store depletion by incubation in TG. We attribute this delay to the time required to achieve the low level of bath $\mathrm{Ca}^{2+}$ that is necessary to allow nonselective conductance, for which reported $K_{\mathrm{d}}$ range from 1.7 to $4.5 \mu \mathrm{M}$ (Lepple-Wienhues and Cahalan, 1996; Kerschbaum and Cahalan, 1998; Rychkov et al., 2001). Specifically, an exponential model incorporating the bath volume $(0.7 \mathrm{ml})$ and inflow rate $(3.3 \mathrm{ml} / \mathrm{min})$ predicts 110 and $98 \mathrm{~s}$ to reach these levels of bath $\mathrm{Ca}^{2+}$, although imperfect mixing may cause faster washout in the central area used for recording. Sensory neurons did not show the fast depotentiation of DVF-induced $I_{\text {CRAC }}$ as has been noted in other cells and expression systems (Zweifach and Lewis, 1996; DeHaven et al., 2007; Smyth et al., 2008). Return of $\mathrm{Ca}^{2+}$ to the bath resulted in immediate termination of $\mathrm{Na}^{+}$permeation (Fig. 4D). Additional recognition of the observed current as $I_{\text {CRAC }}$ was obtained through the application of $\mathrm{La}^{3+}(10 \mu \mathrm{M})$, an established blocker of $I_{\text {CRAC }}$ (Hoth and Penner, 1993), which elimi- nated $62 \%$ of the current initiated by DVF solution in TG-treated neurons ( $p<0.05$ vs neurons without TG) (Fig. $4 D, E$ ).

\section{Identification of molecular components of SOCE}

STIM1 protein has previously been confirmed in neuronal tissues (Gasperini et al., 2009; Klejman et al., 2009), but not in adult sensory neurons, whereas Orail has been colocalized with STIM1 in brain neurons (Klejman et al., 2009). In DRG neurons, we have found expression of both components of SOCE in sensory neurons at the protein level by immunoblotting (Fig. $5 A, B$ ) and at the transcript level by quantitative rtPCR (Fig. $5 C)(n=3$ control animals for both determinations), indicating that STIM1 and Orail are available in sensory neurons as potential constituents of SOCE. Immunohistochemistry of DRG tissue from control animals $(n=3)$ revealed the presence of STIM1 in neuronal somata as a homogeneous distribution in the cytoplasm (Fig. 6A), consistent with its location in the ER. There was no preferential expression of STIM1 in DRG subpopulations of different neuronal size (Fig. 6B). Double staining for STIM1 with NeuN, a neuronspecific marker (Fig. 6A), revealed expression of STIM1 in all neurons. Using glutamine synthetase as a marker for satellite glial cells (Weick et al., 2003) demonstrated that STIM1 is also present in the cytoplasm of satellite glial cells. Since available antibodies to Orail protein reacted with nonspecific bands in immunoblotting, immunohistochemical selectivity could not be assured and anatomic identification was not performed.

\section{Functional role of SOCE in sensory neurons}

The influence of SOCE on neuronal function is poorly defined (Putney, 2003). SOCE has been noted to modulate resting $\left[\mathrm{Ca}^{2+}\right]_{\mathrm{c}}$ in rat sympathetic neurons (Wanaverbecq et al., 2003). We found that most (57 of $71 ; 80 \%$ ) sensory neurons responded to $\mathrm{Ca}^{2+}$ withdrawal with a fall in $\left[\mathrm{Ca}^{2+}\right]_{\mathrm{c}}$ (Fig. $1 \mathrm{~A}$ ) by $17 \pm 3 \mathrm{nM}$ $\left(p<0.001\right.$ withdrawal vs baseline) after $7 \mathrm{~min}$ exposure to $\mathrm{Ca}^{2+}$. free bath (Fig. 7A), which indicates a dependence of resting $\left[\mathrm{Ca}^{2+}\right]_{\mathrm{c}}$ on ongoing SOCE. In a subset of neurons, we extended the interval of $\mathrm{Ca}^{2+}$ withdrawal to $30 \mathrm{~min}$, but did not observe any significant difference compared with the $7 \mathrm{~min}$ interval (14 \pm $2 \mathrm{~nm} ; p<0.001$, withdrawal vs baseline; $p=0.42$ for 7 vs $30 \mathrm{~min}$ ).

Neurons, particularly slowly conducting C-type neurons with small-diameter somata, may remain quiescent for a sustained period of time (Schmidt et al., 1995). Since extrusion of cytoplasmic $\mathrm{Ca}^{2+}$ by the plasma membrane $\mathrm{Ca}^{2+}$-ATPase continues in resting neurons (Wanaverbecq et al., 2003), SOCE may be an important source of $\mathrm{Ca}^{2+}$ influx for maintaining intracellular stores during inactivity. To test this, resting sensory neurons were incubated in $\mathrm{Ca}^{2+}$-free bath solution for various time intervals and then exposed to $20 \mathrm{~mm}$ caffeine, which leads to a quantifiable emptying of $\mathrm{Ca}^{2+}$ stored in the ER (Rigaud et al., 2009). Releasable $\mathrm{Ca}^{2+}$ significantly decreased after $7 \mathrm{~min}$ in $\mathrm{Ca}^{2+}$-free bath and even more after $30 \mathrm{~min}$ (Fig. $7 \mathrm{~B}$ ), revealing a constitutive role of SOCE in the maintenance of intraneuronal $\mathrm{Ca}^{2+}$ store levels.

$\mathrm{Ca}^{2+}$ stores in sensory neurons may be depleted through the activation of metabotropic receptors, such as those for bradykinin, ATP, and glutamate (Thayer et al., 1988; Crawford et al., 2000; Kruglikov et al., 2004), or by activation of high-affinity TRPV1 channels on the ER (Liu et al., 2003). In the absence of neuronal depolarization, the SOCE influx pathway may serve a critical role in generating plasmalemmal $\mathrm{Ca}^{2+}$ influx for replenishing $\mathrm{Ca}^{2+}$ stores. We found that $\mathrm{Ca}^{2+}$ stores, measured by release with caffeine $(20 \mathrm{~mm})$, recover almost completely during 10 min with $2 \mathrm{~mm}$ bath $\mathrm{Ca}^{2+}$ (second transient compared with first; amplitude, $89 \pm 5 \%$; area, $72 \pm 3 \%$; $n=26$ ) (Fig. $7 C$ ), but 
recovery fails in the absence of bath $\mathrm{Ca}^{2+}$ (amplitude, $5 \pm 2 \%$; area, $3 \pm 1 \%$; $n=$ $14)$, indicating that SOCE is needed for replenishing intraneuronal $\mathrm{Ca}^{2+}$ stores after a release event.

Effect of painful nerve injury on SOCE In previous studies, we found that nerve injury depresses resting $\left[\mathrm{Ca}^{2+}\right]_{\mathrm{c}}$ and diminishes $\mathrm{Ca}^{2+}$ stores (Fuchs et al., 2005; Gemes et al., 2009; Rigaud et al., 2009). Since our present findings show that SOCE functions to maintain intracellular levels of cytoplasmic and releasable $\mathrm{Ca}^{2+}$, we examined the possibility that SOCE is deficient after peripheral nerve injury by SNL, a standard model of neuropathic pain. This proved not to be the case. The amplitude of the SOCE transient on $\mathrm{Ca}^{2+}$ readdition was increased in axotomized L5 neurons after SNL compared with neurons from control animals, after both 7 and 30 min of $\mathrm{Ca}^{2+}$ withdrawal, whereas there was no effect on adjacent L4 neurons (Fig. 8A). Analysis of the transient slope similarly showed an amplification of SOCE after injury (Fig. $8 \mathrm{~A}$ ). In contrast, when SOCE was maximized by store depletion with TG, transient amplitude and slope in injured SNL L5 neurons were no different from control neurons (Fig. $8 B$ ), implying that injured neurons have increased regulatory drive for SOCE but not increased maximal efficacy of SOCE.

To determine whether STIM1 and Orail expression is affected by injury, levels of protein and transcript of both genes were measured after SNL. The levels of STIM1 and Orail protein determined by immunoblotting were not significantly different between the DRGs of control $(n=3)$ and injured $(n=3)$ animals (STIM1, $p=0.12$; Orai1, $p=0.73$ ) (Fig. $5 B)$. Similarly, quantitative rtPCR analysis (Fig. 5C) indicated that transcript levels of STIM1 $(p=0.67)$ and Orai1 $(p=0.49)$ in L5 DRGs of control animals $(n=3)$ and L4 and L5 DRGs of the injured animals $(n=3)$ were comparable. The anatomical distribution of STIM1 in L4 and L5 DRG sections from SNL animals $(n=$ 3) double stained for STIM1 and NeuN were not different from control findings described above (Fig. 6A). These analyses together indicate that STIM1 and Orail expression is not altered by peripheral nerve injury.

Direct measurement of $I_{\text {CRAC }}$ induced by DVF conditions in injured SNL L5 neurons again showed delays in onset of the current (without TG, $105 \pm 21 \mathrm{~s} ; n=8$; with TG, $77 \pm 18 \mathrm{~s} ; n=6)$. In the absence of store depletion, $I_{\text {CRAC }}$ was greater in SNL L5 neurons $(-4.15 \pm$ $0.64 \mathrm{pA} / \mathrm{pF} ; n=8)$ than in control neurons $(-0.41 \pm 0.14 \mathrm{pA} / \mathrm{pF}$;
A $\mathrm{I}_{\text {CRAC }}$ during $\mathrm{Ca}^{2+}$
readdition
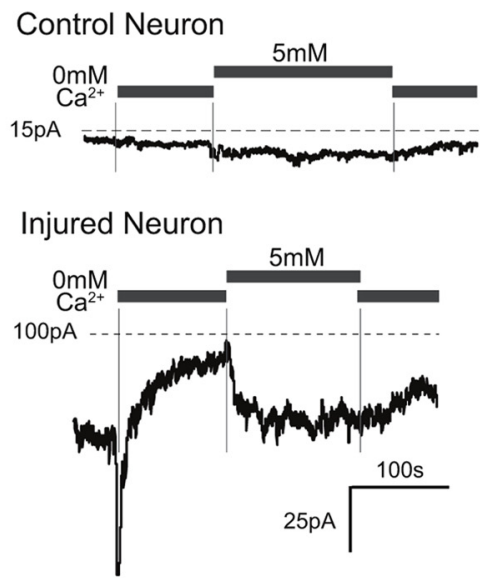

B $\mathrm{I}_{\text {CRAC }}$ during hyper-

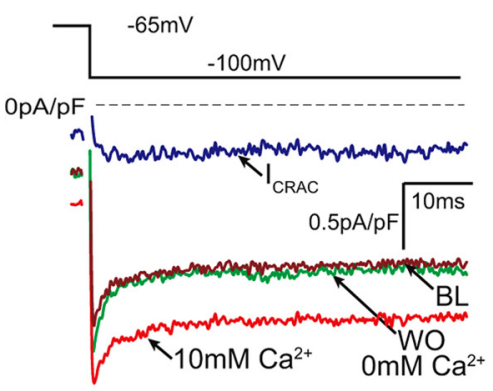

C $\mathrm{I}_{\mathrm{CRAC}}$ during ramp depolarization

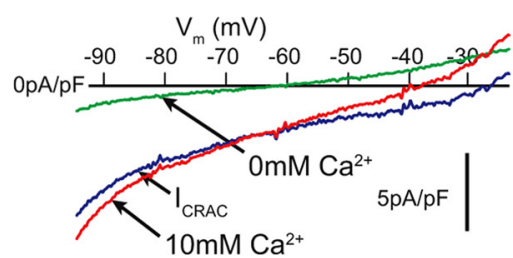

Figure 4. Recording of the $\mathrm{Ca}^{2+}$ release-activated current $\left(I_{\mathrm{CRAC}}\right) \cdot A$, Withdrawal of bath $\mathrm{Ca}^{2+}$ lowers inward current, and readdition of bath $\mathrm{Ca}^{2+}(5 \mathrm{~mm})$ elevates current during voltage clamp $(-65 \mathrm{mV})$ of a control neuron $(30 \mu \mathrm{m}$ diameter; top panel) and an injured neuron ( $30 \mu \mathrm{m}$; bottom panel) by SOCE. The scale bars apply to both traces. $\boldsymbol{B}$, Current traces generated during step hyperpolarizations in a control neuron $(30 \mu \mathrm{m})$. The baseline trace $(\mathrm{BL})$ was during 0 bath $\mathrm{Ca}^{2+}$. Inward current induced by hyperpolarization increased during $10 \mathrm{~mm}$ bath $\mathrm{Ca}^{2+}$ and returned to baseline levels with washout of $\mathrm{Ca}^{2+}$ from the bath (W0). The difference current (baseline trace subtracted from the $10 \mathrm{~mm} \mathrm{Ca}^{2+}$ trace) represents $I_{\mathrm{CRAC}}$. (Typical of $n=5$.) $C$, Presentation of a ramp depolarizing voltage command (12 $\mathrm{mV} / \mathrm{ms}$ ) generates current (plotted here against voltage) in a control neuron $(28 \mu \mathrm{m})$ that is less with 0 bath $\mathrm{Ca}^{2+}$ than during $10 \mathrm{~mm}$ bath $\mathrm{Ca}^{2+}$. The difference trace represents $I_{\mathrm{CRAC}}$. Outward current is carried by $\mathrm{K}^{+}$channels that were sensitive to (data not shown), but incompletely blocked by, bath TEA $(50 \mathrm{mM})$. The $I_{\text {CRAC }}$ trace shows inward rectification, with an inflection at approximately $-34 \mathrm{mV}$, above which $\mathrm{Ca}^{2+}$-sensitive $\mathrm{K}^{+}$current contributes an outward component. (Typical of $n=5$.) D, After incubation in TG (1 $\mu \mathrm{m}$ for $7 \mathrm{~min}$ ), exposing a control neuron $(32 \mu \mathrm{m}$ ) to bath solution lacking divalent cations (DVF) produced a large inward current through the storeoperated $\mathrm{Ca}^{2+}$ channels, which is blocked by $\mathrm{La}^{3+}(10 \mu \mathrm{M})$. $\boldsymbol{E}$, Data from experiments such as shown in $\boldsymbol{D}$. In control neurons (top panel), DVF produces minimal current under baseline conditions in the absence of store depletion (filled circles). In separate control neurons incubated in TG (open circles), DVF produces large inward currents that are blocked by La ${ }^{3+}$. Injured neurons (SNL L5; bottom panel) show greater DVF-induced currents without store depletion by TG (filled squares), which are not significantly altered by TG (open squares). Shown are mean \pm SEM. ${ }^{*} p<0.05 ;{ }^{* *} p<0.01$. $n=6 ; p<0.01$ ) (Fig. $4 E$ ), indicating that $I_{\text {CRAC }}$ is increased in sensory neurons after nerve injury. TG failed to have a significant effect on measured $I_{\text {CRAC }}$ in injured neurons (average, $-7.04 \pm$ $2.67 \mathrm{pA} / \mathrm{pF} ; n=6$ ) (Fig. $4 E$ ), suggesting that injury itself depletes 


\section{A Western Blot}

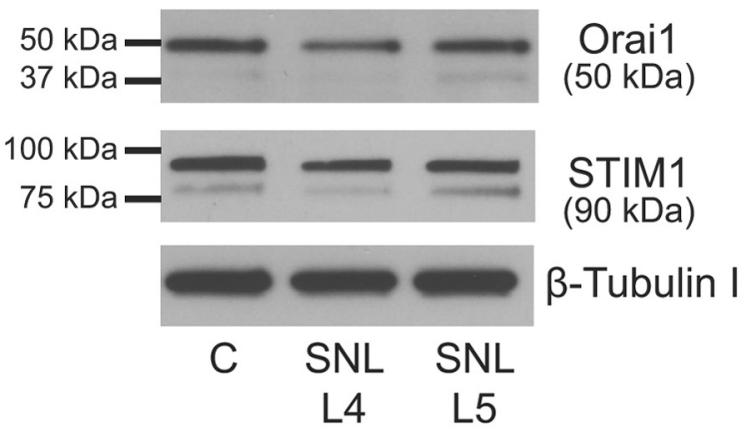

B Western Blot quantification

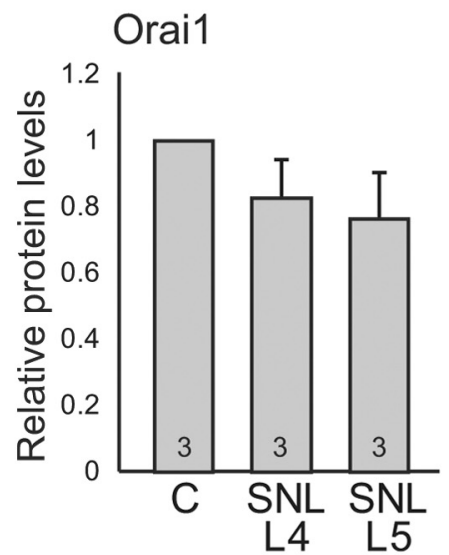

STIM1

C Quantitative rtPCR

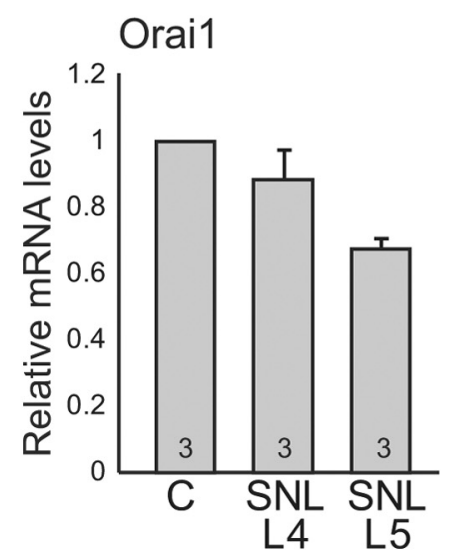

STIM1
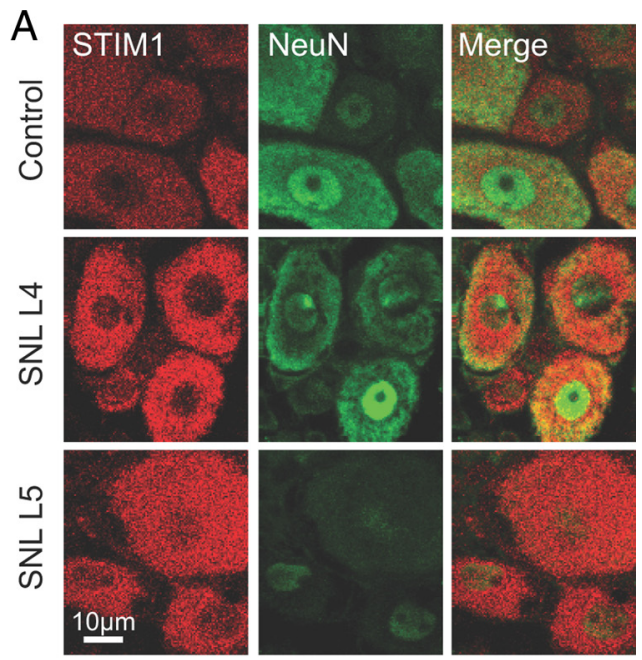

B STIM1 immunofluorescence
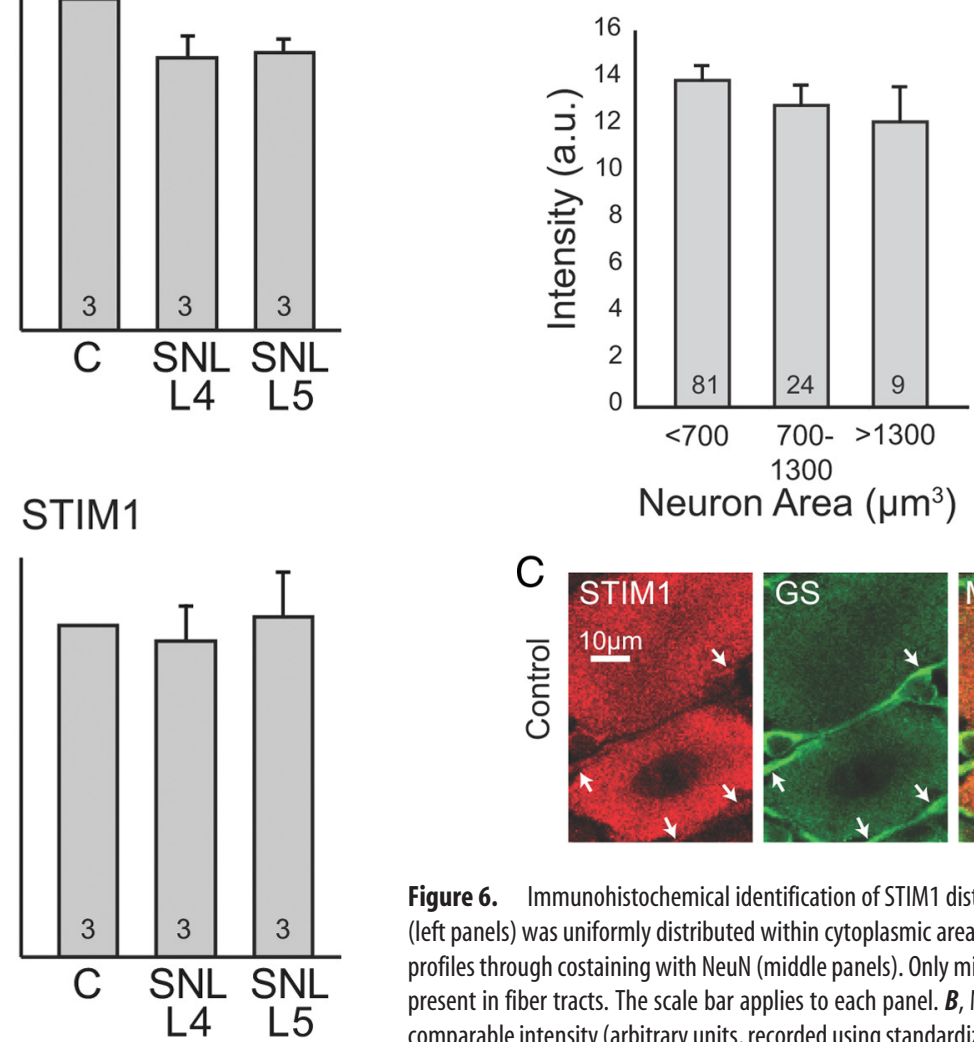

Figure 5. Identification of molecular components of store-operated $\mathrm{Ca}^{2+}$ channels. $\boldsymbol{A}$, Western blotting detected Orai1 and STIM1 proteins in lysates from control (C) dorsal root ganglia (DRG), from fourth lumbar DRGs after fifth lumbar spinal nerve ligation (SNL L4), and from axotomized fifth lumbar DRGs after SNL (SNL L5). A dominant STIM1 band at the expected molecular weight is accompanied by a closely coherent secondary band that others have shown to be sensitive to STIM1 knockdown by RNAi (Ong et al., 2007). (Typical of $n=3$.) B, Quantification of Western blots as fold difference compared with control showed no effect of injury on Orai1 and STIM1 protein levels. Shown are mean \pm SEM. C, Quantification of transcript levels by quantitative rtPCR also showed no effects of injury on 0rai1 and STIM1 expression. For $\boldsymbol{B}$ and $\boldsymbol{C}$, the numbers in bars indicate $n$.

stores and activates $I_{\mathrm{CRAC}}$. After store depletion by TG, there is little difference in DVF-induced $I_{\text {CRAC }}$ between injured neurons $(-7.04 \pm 2.67 \mathrm{pA} / \mathrm{pF})$ and control neurons $(-6.44 \pm 1.22 \mathrm{pA} /$ pF) (Fig. 4E). These findings, together with lack of effect of injury on $\mathrm{Ca}^{2+}$ readdition transients after TG and comparable expres-

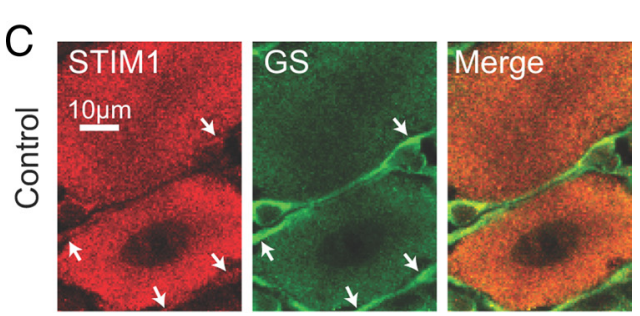

Figure 6. Immunohistochemical identification of STIM1 distribution. $\boldsymbol{A}$, Staining for STIM1 (left panels) was uniformly distributed within cytoplasmic areas of cells identified as neuronal profiles through costaining with NeuN (middle panels). Only minimal nonspecific staining was present in fiber tracts. The scale bar applies to each panel. $\boldsymbol{B}$, Morphometric analysis showed comparable intensity (arbitrary units, recorded using standardized image acquisition) of staining in neurons of all sizes (ANOVA, $p=0.40$ ). Shown are mean \pm SEM. C, STIM1 (left panel) was also found in cellular components identified as satellite glial cells by their expression of glutamine synthase (GS) (middle panel). Identically placed arrows in the left and middle panels indicate cellular areas clearly identifiable as satellite glial cell cytoplasm that expresses STIM1. The scale bar applies to each panel.

sion of molecular subunits after injury, suggest that injury activates SOCE through store depletion but does not alter the intrinsic capacity of SOCE.

Injured neurons demonstrate an elevated dependence on SOCE. Although resting $\left[\mathrm{Ca}^{2+}\right]_{\mathrm{c}}$ is depressed in injured neurons $(54 \pm 4 \mathrm{nM} ; n=30)$ compared with control neurons ( $66 \pm 3 \mathrm{nM}$; $n=57 ; p<0.05)$ and adjacent SNL L4 neurons $(70 \pm 3 \mathrm{nM} ; n=$ 24; $p<0.05)$, termination of SOCE by bath $\mathrm{Ca}^{2+}$ withdrawal imposes additional depression of $\left[\mathrm{Ca}^{2+}\right]_{\mathrm{c}}$ (Fig. $7 \mathrm{~A}$ ), provoking much lower $\left[\mathrm{Ca}^{2+}\right]_{\mathrm{c}}$ after injury in SNL L5 neurons (34 $\left.\pm 2 \mathrm{nM}\right)$ 


\section{A Bath $\mathrm{Ca}^{2+}$ withdrawal lowers
resting $\left[\mathrm{Ca}^{2+}\right]_{\mathrm{c}}$}

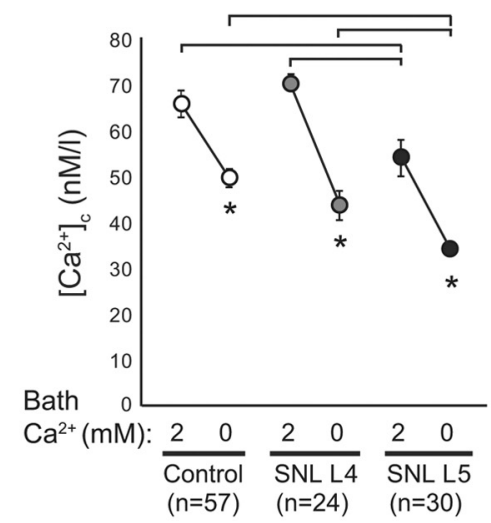

B Bath $\mathrm{Ca}^{2+}$ withdrawal depletes caffeinereleasable $\mathrm{Ca}^{2+}$ stores

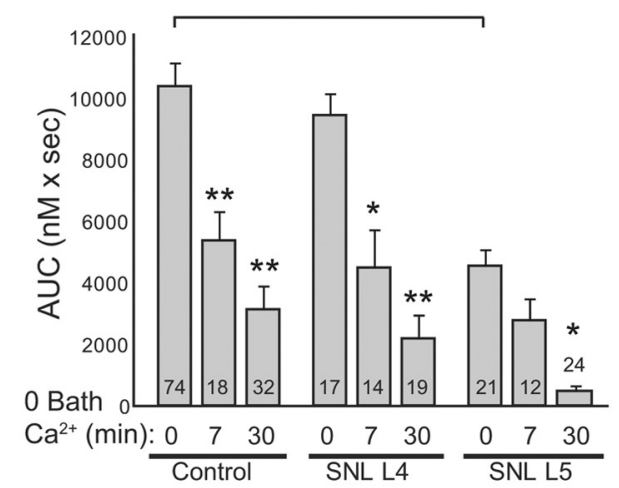

\section{SOCE refills $\left[\mathrm{Ca}^{2+}\right]_{\mathrm{c}}$ stores at rest}

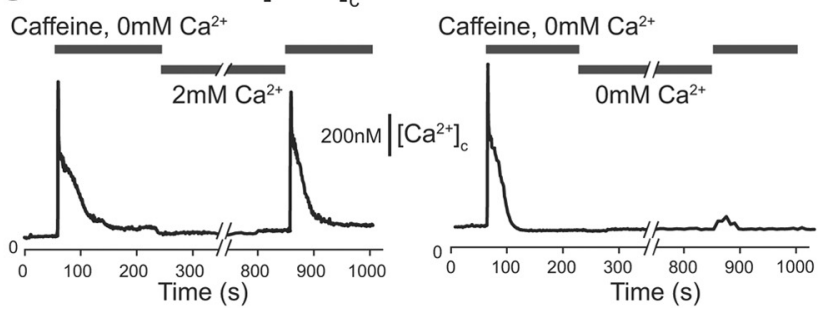

Figure 7. Functional roles of SOCE. $A$, Decreasing bath $\mathrm{Ca}^{2+}$ from 2 to $0 \mathrm{~mm}$ reduced $\left[\mathrm{Ca}^{2+}\right]_{\mathrm{c}}$ in control (C) neurons, as well as in fifth lumbar ( $L 5$ ) neurons axotomized by SNL and those in the adjacent $L 4$ dorsal root ganglion $\left({ }^{*} p<0.05\right)$. SNL $L 5$ neurons had lower resting $\left[\mathrm{Ca}^{2+}\right]_{\mathrm{c}}$ levels before and after bath $\mathrm{Ca}^{2+}$ withdrawal compared with control and SNL L4 neurons (brackets). B, The size of intracellular $\mathrm{Ca}^{2+}$ stores that are releasable by caffeine $(20 \mathrm{~mm})$, measured as the area under the curve (AUC) of the caffeine-induced $\left[\mathrm{Ca}^{2+}\right]_{\mathrm{c}}$ transient, was diminished by withdrawal of bath $\mathrm{Ca}^{2+}$ for 7 and 30 min compared with baseline conditions $\left(0\right.$ min of $\mathrm{Ca}^{2+}$ withdrawal; ANOVA main effect for time in 0 bath $\mathrm{Ca}^{2+}{ }^{2+} p<0.001$; paired comparisons, ${ }^{*} p<$ $0.05,{ }^{* *} p<0.01$ ). Stores are reduced in SNL L5 neurons before bath $\mathrm{Ca}^{2+}$ withdrawal (ANOVA main effect for injury group, $p<0.001$; bracket indicates $p<0.01$ for paired comparison). The numbers in the bars indicate number of neurons. Shown are mean \pm SEM. C, Absence of bath $\mathrm{Ca}^{2+}$ prevents refilling of intracellular $\mathrm{Ca}^{2+}$ stores. Caffeine $(20 \mathrm{~mm})$ releases stored $\mathrm{Ca}^{2+}$ in a control neuron ( $29 \mu \mathrm{m}$ diameter; left panel), which is replenished during $10 \mathrm{~min}$ in $2 \mathrm{~mm}$ bath $\mathrm{Ca}^{2+}$, as shown by a second caffeine-induced transient of almost equal size. In another neuron (32 $\mu \mathrm{m}$; right panel), absence of bath $\mathrm{Ca}^{2+}$ after $\mathrm{Ca}^{2+}$ store depletion results in a much reduced release of $\mathrm{Ca}^{2+}$ by the second caffeine application. The scale bar applies to both traces.

than in control conditions $(50 \pm 2 \mathrm{nM} ; p<0.001)$ and SNL L4 neurons ( $44 \pm 3 \mathrm{~nm} ; p<0.05)$. The level of stored $\mathrm{Ca}^{2+}$ in resting sensory neurons is also diminished by injury (Fig. $7 B$ ) (Rigaud et al., 2009). Elimination of SOCE has a particularly severe effect on
$\mathrm{Ca}^{2+}$ stores in injured neurons, such that SNL L5 neurons retain only $10 \%$ of their original stored $\mathrm{Ca}^{2+}$ after $30 \mathrm{~min}$ of SOCE termination through bath $\mathrm{Ca}^{2+}$ removal, compared with retention of $33 \%$ by control neurons and $23 \%$ by SNL L 4 neurons. The combined effect of injury and SOCE termination reduces $\mathrm{Ca}^{2+}$ stores to $4 \%$ of that in baseline control neurons (Fig. 7B). Together, these observations indicate that SOCE plays an amplified role in maintaining $\mathrm{Ca}^{2+}$ homeostasis after axonal trauma in sensory neurons.

\section{SOCE regulation of neuronal excitability}

We have previously observed that blockade of $\mathrm{Ca}^{2+}$-induced $\mathrm{Ca}^{2+}$ release (CICR) from intracellular stores increases sensory neuron excitability associated with a decreased AHP duration (Gemes et al., 2009). We therefore reasoned that store depletion from loss of SOCE might have a comparable effect. We chose not to eliminate SOCE by bath $\mathrm{Ca}^{2+}$ withdrawal since this can directly increase membrane excitability, independent of the loss of SOCE, by disrupting membrane charge and by decreasing depolarization-induced $I_{\mathrm{Ca}}$ through voltage-gated channels, which in turn decreases $\mathrm{Ca}^{2+}$-activated $\mathrm{K}^{+}$currents and AHPs that follow APs (Lirk et al., 2008). We instead examined the effects of SOCE blockade while recording transmembrane potentials from small- to medium-sized neurons, using an intracellular electrode technique in excised but intact DRGs that avoids the excitatory influence of neuronal dissociation (Zheng et al., 2007). Since $\mathrm{La}^{3+}$ is a nonselective blocker of $\mathrm{Ca}^{2+}$ channels including VGCCs, we therefore used TRIM $(200 \mu \mathrm{M})$ as the best available blocker despite its incomplete efficacy (Fig. 3B). We paired recordings on each day such that an L5 DRG from a control animal was incubated in TRIM and its other L5 DRG was incubated in vehicle ( $0.2 \% \mathrm{DMSO})$ for $30 \mathrm{~min}$, randomizing the sequence. For injured neurons, two L5 DRGs ipsilateral to an SNL injury were harvested from two different animals, and used in a similar paired fashion. There was no effect of TRIM on RMP or AP width (Table 1), comparable with previous findings in neurons of the supraoptic nucleus (Tobin et al., 2006). In vehicle-treated neurons, injury produced longer AP duration and decreased rheobase, as has been noted previously (Sapunar et al., 2005). TRIM increased the rheobase current necessary for initiating an AP in both control and injured neurons, and additionally decreased input resistance and lowered voltage threshold for AP generation in injured neurons. The late phase of the AHP is produced by the slow SK isoform of the $\mathrm{Ca}^{2+}$-activated $\mathrm{K}^{+}$channel, which is particularly dependent on $\mathrm{Ca}^{2+}$ released from stores. We therefore examined AHP duration, which was decreased by TRIM, particularly in injured neurons. The duration of the AHP regulates repetitive firing behavior of sensory neurons (Sapunar et al., 2005). We evaluated this by injection of suprathreshold depolarizing currents, which produced either a repetitive firing pattern (Fig. 9A) or a completely accommodating pattern in which only a single spike was generated despite depolarization beyond threshold (Fig. 9B). TRIM increased the incidence of repetitively firing neurons in both control and injured neurons. In these repetitively firing neurons, we characterized neuronal excitability further by plotting the number of evoked APs at each membrane potential, for which the slope of the fitted line represents the gain of the relationship. TRIM increased the gain in both control neurons (DMSO, $0.13 \pm 0.02 \mathrm{APs} / \mathrm{mV}, n=6$; TRIM, $0.28 \pm 0.06, n=12$ ) and injured neurons (DMSO, $0.13 \pm 0.02 \mathrm{APs} / \mathrm{mV}, n=6$; TRIM, $0.20 \pm 0.03, n=18$; ANOVA main effect of TRIM, $p<0.01$ ), showing that blockade of SOCE elevates neuronal burst firing generally. Although there is a higher resting level of SOCE in 


\section{A $\mathrm{Ca}^{2+}$ readdition transients after injury}
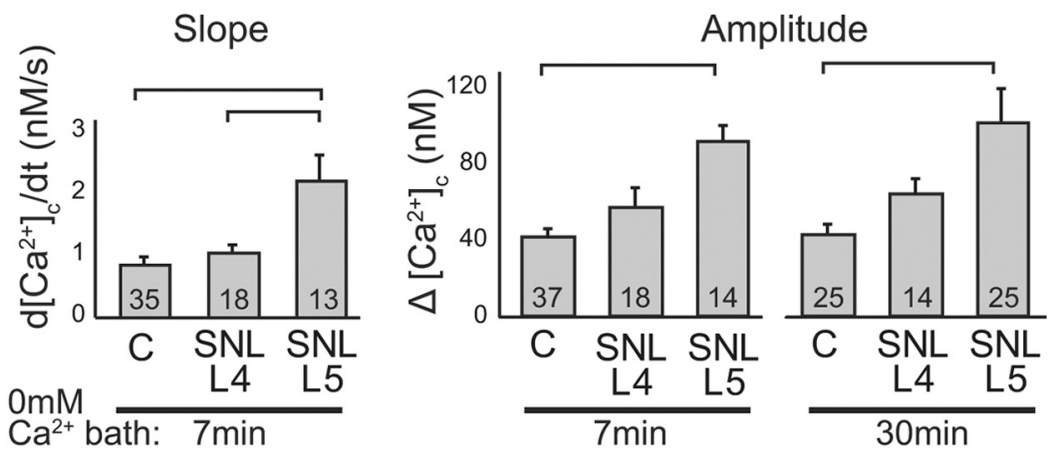

\section{B $\mathrm{Ca}^{2+}$ readdition transients after injury and thapsigargin}
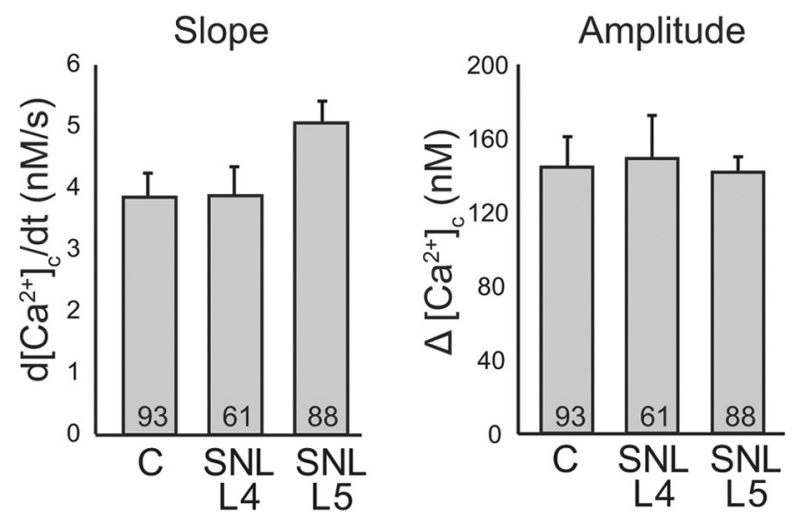

Figure 8. Effect of injury by SNL on the axotomized fifth lumbar ( $L 5)$ and $L 4$ neurons compared with control (C) neurons. $A$, Both the maximum slope of the $\left[\mathrm{Ca}^{2+}\right]_{\mathrm{c}}$ trace and the amplitude of the transient induced by $\mathrm{Ca}^{2+}$ readdition are increased in $\mathrm{LS}$ neurons after SNL (ANOVA main effect for injury group, $p<0.01$; bracket indicates $p<0.05$ for paired comparison). Increasing the time of $\mathrm{Ca}^{2+}$ withdrawal from 7 to 30 min has no effect on the amplitude of readdition transients. $\boldsymbol{B}$, Maximizing store-operated $\mathrm{Ca}^{2+}$ entry by store depletion with thapsigargin incubation $(1 \mu \mathrm{m} ; 7 \mathrm{~min})$ increased average transient slope and amplitude compared with transients without thapsigargin (shown in $\boldsymbol{A}$ ) and eliminated the influence of injury because of a diminished effect on SNL L5 neurons. The numbers in the bars indicate number of neurons. Shown are mean \pm SEM.

injured neurons, we did not demonstrate a difference in the effect of TRIM on excitability of control and injured neurons, possibly because TRIM leaves 39\% of SOCE intact (Fig. 3).

Apart from blocking SOCE, TRIM may also inhibit neuronal nitric oxide synthase (NOS) (Handy et al., 1995; Gibson et al., 2001), and NO may affect voltage-gated $\mathrm{Ca}^{2+}$ and $\mathrm{Na}^{+}$currents in DRG neurons (Kim et al., 2000; Renganathan et al., 2000). We therefore examined the effect of incubating control neurons with 7-NI (200 $\mu \mathrm{M} ; n=22)$, a selective neuronal NOS inhibitor (Moore et al., 1993), which produced no elevation of repetitive firing compared with neurons of matched ganglia incubated in vehicle $(0.1 \% \mathrm{DMSO} ; n=19)$. From these findings, we infer that the increased repetitive firing of DRG neurons produced by TRIM is the result of loss of SOCE.

\section{Influence of store depletion on depolarization-induced $\mathrm{Ca}^{2+}$ influx}

Recent reports indicate that STIM1, when activated by store depletion, suppresses $\mathrm{Ca}^{2+}$ influx through L-type VGCCs (Park et al., 2010; Wang et al., 2010). To determine whether this regulatory pathway functions in sensory neurons, we incubated neurons from uninjured animals for $30 \mathrm{~min}$ in normal $\mathrm{Ca}^{2+}$ bath containing TRIM $(200 \mu \mathrm{M})$ or vehicle $(0.2 \%$ DMSO). Thereafter, the bath was changed to a solution in which $\mathrm{Ca}^{2+}$ was replaced by
$\mathrm{Sr}^{2+}$ to block SOCE, and dantrolene (10 $\mu \mathrm{M}$ ) was added to block CICR from stores. After $1 \mathrm{~min}$ in this solution, neuronal depolarization (rapid bath application of $\mathrm{K}^{+}, 50 \mathrm{~mm}, 3 \mathrm{~s}$ ) triggered $\mathrm{Sr}^{2+}$ entry through VGCCs, which produced transients in TRIM-treated neurons that had diminished amplitudes (TRIM, $0.81 \pm$ $0.12 R$ units, $n=18$; DMSO, $1.08 \pm 0.08 R$ units, $n=29$; $p<0.05)$ and initial slopes (TRIM, $0.54 \pm 0.07 R$ units/s, $n=18$; DMSO, $0.76 \pm 0.07 R$ units/s, $n=29 ; p<$ 0.05) compared with DMSO control. These diminished transients are unlikely to be attributable to decreased CICR from TRIM-depleted stores since dantrolene will have blocked CICR in both DMSO and TRIM groups. Also, it is known that TRIM at a 10-fold higher concentration does not directly block VGCCs (Tobin et al., 2006). So, in addition to regulating SOCE, it is likely that STIM1 activation in sensory neurons inhibits VGCCs, which may in turn contribute to elevated neuronal excitability (Lirk et al., 2008).

\section{Discussion}

Our data confirm and extend previous observations that infer the presence of SOCE in central and peripheral neurons. In sensory neurons from neonatal rats, Usachev and Thayer (1999) have shown that replenishment of intracellular stores requires bath $\mathrm{Ca}^{2+}$. They and others (Liu et al., 2003; Lu et al., 2006) have observed SOCE activity through the rise in $\left[\mathrm{Ca}^{2+}\right]_{c}$ on return of $\mathrm{Ca}^{2+}$ to the bath solution, which is modulated by store level (Usachev and Thayer, 1999). We have confirmed that SOCE, represented by the readdition transient, is a general feature of acutely dissociated adult neurons, including putative nociceptors with small diameters and capsaicin sensitivity, as well as large, capsaicininsensitive non-nociceptive neurons. Both the depletion of stores by SERCA blockade and the chelation of stores by TPEN result in amplification of the transient, suggesting the regulation of SOCE by store level. Calcium influx on return of bath $\mathrm{Ca}^{2+}$ cannot be attributed to currents through VGCCs or to changes in membrane potential. Although the pharmacological tools for manipulating SOCE are poorly developed, blockers that have proved successful in other reports, including $\mathrm{La}^{3+}$, TRIM, and 2-APB, showed efficacy in reducing the readdition transient in sensory neurons. These observations provide strong inferential support for the existence of SOCE in sensory neurons.

We have also been able to obtain direct evidence of SOCE in neurons through the recording of $I_{\text {CRAC }}$. Although this current is very small at RMP, we identified an inward current component during step hyperpolarizations or ramp depolarizations that depended on the presence of external $\mathrm{Ca}^{2+}$ and exhibited inward rectification, which are characteristics of $I_{\text {CRAC }}$. The development of large inward $\mathrm{Na}^{+}$flux on removal of divalent cations from the bath solution has been shown to be a typical feature of SOCE in nonexcitable cells and expression systems (Hoth and Penner, 
Table 1. Electrophysiological behavior of control and injured fifth lumbar dorsal root ganglion neurons during either blockade of store-operated $\mathrm{Ca}^{2+}$ entry with TRIM $(200 \mu \mathrm{M})$ or application of vehicle (DMSO, $0.2 \%)$

\begin{tabular}{|c|c|c|c|c|c|c|}
\hline & \multicolumn{4}{|c|}{ Injury group/treatment group } & & \\
\hline & \multicolumn{2}{|l|}{ Control } & \multicolumn{2}{|c|}{ Spinal nerve ligation } & \multicolumn{2}{|c|}{ ANOVA main effects } \\
\hline & $\operatorname{DMSO}(n=23)$ & $\operatorname{TRIM}(n=19)$ & $\operatorname{DMSO}(n=46)$ & $\operatorname{TRIM}(n=57)$ & Injury & Treatment \\
\hline Diameter ( $\mu \mathrm{m})$ & $30 \pm 1$ & $28 \pm 1$ & $30 \pm 1$ & $31 \pm 1$ & NS & NS \\
\hline $\mathrm{RMP}(\mathrm{mV})$ & $-53.3 \pm 1.9$ & $-52.4 \pm 1.9$ & $-54.0 \pm 1.0$ & $-55.1 \pm 1.1$ & NS & NS \\
\hline$R_{\text {in }}(\mathrm{M} \Omega)$ & $63.1 \pm 6.0$ & $58.9 \pm 10.3$ & $99.0 \pm 11.5$ & $56.4 \pm 7.3^{*}$ & NS & 0.002 \\
\hline AP duration (ms) & $1.4 \pm 0.2$ & $1.2 \pm 0.2$ & $2.3 \pm 0.2^{\dagger}$ & $2.2 \pm 0.2^{\dagger}$ & $<0.001$ & NS \\
\hline AHP amplitude (mV) & $18.2 \pm 1.1$ & $20.0 \pm 1.7$ & $10.0 \pm 0.9^{\dagger}$ & $12.2 \pm 0.8^{\dagger}$ & $<0.001$ & 0.045 \\
\hline AHP duration (ms) & $3.6 \pm 0.5$ & $3.0 \pm 0.4$ & $4.5 \pm 0.5$ & $3.4 \pm 0.2$ & NS & 0.020 \\
\hline Rheobase (nA) & $1.36 \pm 0.15$ & $2.37 \pm 0.38^{*}$ & $0.78 \pm 0.07$ & $1.11 \pm 0.08^{\dagger}$ & $<0.001$ & 0.001 \\
\hline AP threshold (mV) & $-12.9 \pm 3.4$ & $-12.8 \pm 3.2$ & $-19.8 \pm 2.2$ & $-30.6 \pm 2.0^{t_{*}}$ & $<0.001$ & 0.004 \\
\hline Repetitive firing (\%) & 26 & $59 *$ & 30 & $51^{*}$ & NA & NA \\
\hline
\end{tabular}

RMP, Resting membrane potential; $R_{\text {in }}$, input resistance; AP duration, action potential width measured at $50 \%$ amplitude; AHP duration, width measured at $80 \%$ of afterhyperpolarization amplitude; rheobase, the minimum depolarizing current adequate to produce an AP; AP threshold, the minimal depolarization voltage adequate to produce an AP; repetitive firing, generation of $>1 \mathrm{AP}$ during depolarization to voltages $<30 \mathrm{mV}$. Numbers are average $\pm \mathrm{SEM}$. $n$, Number of neurons; NA, not applicable; NA, not significant $(p>0.05)$.

*Different from DMSO in that injury group, by paired comparisons using Tukey's honest significant difference, except for repetitive firing ( $t$ test), $p<0.05$.

${ }^{\dagger}$ Different from control in that treatment group.

\section{A Repetitive firing during TRIM}
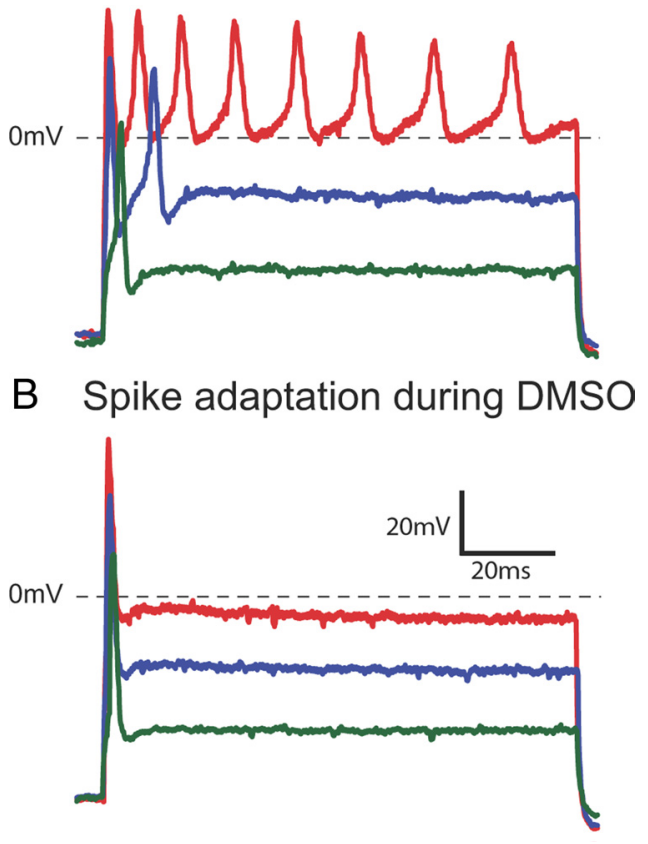

Figure 9. Effect of SOCE blockade on neuronal excitability, showing action potential generation patterns recorded by intracellular electrode in two neurons from the fifth lumbar dorsal root ganglion of rats subjected to spinal nerve ligation, during comparable depolarization (1.2, 2.4, and $3.6 \mathrm{nA})$. Noise is attributable to the use of a switching amplifier ( $2 \mathrm{kHz})$, used to minimize voltage error from current injection through the high-resistance electrode. $A$, Recording from a neuron ( $30 \mu \mathrm{m}$ diameter) incubated with the SOCE blocker TRIM (200 $\mu \mathrm{m}$ for $45 \mathrm{~min}$ ) shows repetitive firing during depolarization past rheobase. $\boldsymbol{B}$, A different neuron $(30 \mu \mathrm{m})$ bathed in vehicle (DMSO, $0.2 \%$ ) demonstrates accommodation, with only a single action potential despite depolarization past rheobase.

1993; DeHaven et al., 2007). We observed a similar phenomenon in sensory neurons. The modulation of the DVF current by store level and bath-applied $\mathrm{La}^{3+}$, an established blocker of SOCE, confirms this current as a representation of $I_{\text {CRAC }}$.

We additionally sought direct evidence of the presence of a SOCE mechanism in sensory neurons through identification of the molecular components underlying the process. There is now substantial agreement on the collaborative roles of STIM1 as the sensor of stored $\mathrm{Ca}^{2+}$, and of Orail as the pore-forming protein seated in the plasmalemma. Expression of these two proteins alone is adequate to generate SOCE, and their colocalization as puncta occurs on store depletion (Putney, 2007a,b). The involvement of canonical transient receptor potential channels (Ong et al., 2007) or the TRPV1 channel (Liu et al., 2003) in storeregulated $\mathrm{Ca}^{2+}$ influx has been proposed, but their participation in SOCE under the control of STIM1 is unlikely (DeHaven et al., 2009). Previous studies of neuronal tissues have identified both STIM1 and Orail in the brain, especially the cerebellum (Klejman et al., 2009), and have located STIM1 in the fetal peripheral nervous system, including the DRG (Dziadek and Johnstone, 2007; Gasperini et al., 2009). Our new data demonstrate the expression of both STIM1 and Orail at the transcript and protein levels in adult sensory neurons, thereby establishing that the molecular hardware for SOCE activity is present in these cells. Our anatomic observations show that STIM1 is present in all neurons, with no difference in intensity between groups of differing neuronal diameter. This is consistent with our findings that SOCE is present during bath $\mathrm{Ca}^{2+}$ readdition in all neurons, without difference in magnitude between subgroups. We identified expression of STIM1 also in satellite glial cells. There is a growing recognition that the close apposition between the sensory neuronal soma and its surrounding satellite glial cells constitutes a functional unit (Hanani, 2005), which may also apply to $\mathrm{Ca}^{2+}$ signaling through a shared extracellular $\mathrm{Ca}^{2+}$ pool.

SOCE serves a clear purpose in nonexcitable cells such as epithelial and blood cells, by providing the dominant $\mathrm{Ca}^{2+}$ entry pathway for replenishing stores and for sustained elevations of $\left[\mathrm{Ca}^{2+}\right]_{\mathrm{c}}$. Identifying functional roles of SOCE in excitable cells that are equipped with high-conductance $\mathrm{Ca}^{2+}$ entry pathways is at an early stage. Support of the resting $\left[\mathrm{Ca}^{2+}\right]_{\mathrm{c}}$ by SOCE has been surmised from the observation of depressed $\left[\mathrm{Ca}^{2+}\right]_{\mathrm{c}}$ after removal of bath $\mathrm{Ca}^{2+}$ in neurons of both the central and peripheral systems (Lipscombe et al., 1989; Nohmi et al., 1992; Wanaverbecq et al., 2003; Szikra et al., 2009), which we have confirmed in adult sensory neurons. Depression of resting $\left[\mathrm{Ca}^{2+}\right]_{\mathrm{c}}$ in neurons may increase sensitivity of the TRPV1 channel (Cholewinski et al., 1993), decrease sensitivity to thermal stimuli (Guenther et al., 1999), and trigger apoptosis (Tsukamoto and Kaneko, 1993; Galli et al., 1995; Bian et al., 1997; Wei et al., 1998). We also identified a dependence on SOCE for maintenance of releasable intracellular $\mathrm{Ca}^{2+}$ stores and their replenishment after release, which confirms previous findings in embryonic sensory neurons (Usachev 
and Thayer, 1999; Cohen and Fields, 2006). In the absence of SOCE, a quiescent neuron would potentially suffer depletion of stores, which may trigger ER stress that involves accumulation of unfolded protein, global suppression of protein synthesis, and activation of a variety of transcription factors, resulting in neuronal dysfunction and apoptosis (Paschen, 2001). Investigations of long-term potentiation in the hippocampus (Emptage et al., 2001; Baba et al., 2003) have revealed that presynaptic SOCE contributes to synaptic plasticity, so spinal cord dorsal horn plasticity may be similarly dependent on sensory neuron SOCE.

The $\mathrm{Ca}^{2+}$ that enters a sensory neuron during AP-induced depolarization provides membrane stabilization through the activation of $\mathrm{Ca}^{2+}$-sensitive $\mathrm{K}^{+}$channels (Hogan et al., 2008; Lirk et al., 2008) The resulting afterhyperpolarization and diminished input resistance that follows each AP limits the impulse generation rate, or may fully eliminate repetitive firing. Release of stored $\mathrm{Ca}^{2+}$ (CICR) contributes to this regulation of spike frequency (Gemes et al., 2009). Additionally, data in the present report show that SOCE functions to suppress neuronal excitability. This raises the possibility that a loss of SOCE contributes to the excessive excitability noted in DRG neurons proximal to an injury (Devor and Seltzer, 1999; Sapunar et al., 2005). Our data have not supported this hypothesis. Rather, we have found that axotomized sensory neurons display amplified SOCE function under baseline conditions. However, pharmacological store depletion reveals an unchanged maximal efficacy of SOCE, and there is no evidence of altered levels of transcript or protein for STIM1 or Orail after injury. Combined with our previous observations of decreased releasable $\mathrm{Ca}^{2+}$ stores and decreased concentration of $\mathrm{Ca}^{2+}$ in the ER lumen after injury (Rigaud et al., 2009), our findings suggest the persistence in axotomized sensory neurons of normally functioning SOCE that is driven into a high activity state by elevated STIM1 triggered by depletion of stores.

Although a normal functioning feedback control response to store depletion satisfactorily explains elevated SOCE activity after neuronal injury, alternative mechanisms accounting for SOCE upregulation might be considered. Recent work has identified regulation of SOCE by signaling pathways involving phosphoinositides (Korzeniowski et al., 2009), tyrosine kinase, which potentiates SOCE (McElroy et al., 2009), and protein kinase C, which inhibits SOCE through phosphorylating Orail (Kawasaki et al., 2010), but there is no direct evidence that shifts in these factors contribute to stimulating SOCE function after injury. $\mathrm{Ca}^{2+} /$ calmodulin-dependent protein kinase II (CaMKII) activates SOCE (Machaca, 2003), but we have found decreased, rather than increased, CaMKII activity in sensory neurons after injury (Kawano et al., 2009; Kojundzic et al., 2010), so the increase of SOCE that we see in injured neurons occurs despite a loss of CaMKII activity.

A supportive role of SOCE in neuronal homeostasis is indicated by the pathogenic consequences of its loss. Although there has been only limited exploration in neurons, the importance of SOCE in neurological disease is highlighted by identification of diminished SOCE in neurons from mice with presenilin-1 mutations related to familial Alzheimer's disease (Yoo et al., 2000), and the direct inhibition of SOCE in hippocampal neurons by mutant presenilin-1 (Herms et al., 2003). In our present study, however, we have identified an apparent compensatory role, since SOCE is increased after injury. Although resting $\left[\mathrm{Ca}^{2+}\right]_{\mathrm{c}}$ and stores are both reduced by injury, the withdrawal of SOCE has a proportionately greater depressive effect on these factors after injury compared with the healthy state. Our data also confirm findings by others (Park et al., 2010; Wang et al., 2010) that store depletion inhibits VGCC function, which elevates excitability in sensory neurons (Lirk et al., 2008). Therefore, supporting $\mathrm{Ca}^{2+}$ store levels by the concurrent activation of SOCE is particularly important so CICR can provide a means to augment the otherwise reduced activity-induced cytoplasmic $\mathrm{Ca}^{2+}$ signal. Our findings expose a particular dependence of injured neurons on SOCE for $\mathrm{Ca}^{2+}$ homeostasis and functional regulation, and highlight the utility of SOCE as a restorative mechanism.

\section{References}

Baba A, Yasui T, Fujisawa S, Yamada RX, Yamada MK, Nishiyama N, Matsuki N, Ikegaya Y (2003) Activity-evoked capacitative $\mathrm{Ca}^{2+}$ entry: implications in synaptic plasticity. J Neurosci 23:7737-7741.

Bian X, Hughes FM Jr, Huang Y, Cidlowski JA, Putney JW Jr (1997) Roles of cytoplasmic $\mathrm{Ca}^{2+}$ and intracellular $\mathrm{Ca}^{2+}$ stores in induction and suppression of apoptosis in S49 cells. Am J Physiol 272:C1241-C1249.

Bootman MD, Collins TJ, Mackenzie L, Roderick HL, Berridge MJ, Peppiatt CM (2002) 2-Aminoethoxydiphenyl borate (2-APB) is a reliable blocker of store-operated $\mathrm{Ca}^{2+}$ entry but an inconsistent inhibitor of InsP3induced $\mathrm{Ca}^{2+}$ release. FASEB J 16:1145-1150.

Braun FJ, Broad LM, Armstrong DL, Putney JW Jr (2001) Stable activation of single $\mathrm{Ca}^{2+}$ release-activated $\mathrm{Ca}^{2+}$ channels in divalent cation-free solutions. J Biol Chem 276:1063-1070.

Caterina MJ, Schumacher MA, Tominaga M, Rosen TA, Levine JD, Julius D (1997) The capsaicin receptor: a heat-activated ion channel in the pain pathway. Nature 389:816-824.

Cholewinski A, Burgess GM, Bevan S (1993) The role of calcium in capsaicin-induced desensitization in rat cultured dorsal root ganglion neurons. Neuroscience 55:1015-1023.

Cohen JE, Fields RD (2006) CaMKII inactivation by extracellular $\mathrm{Ca}^{2+}$ depletion in dorsal root ganglion neurons. Cell Calcium 39:445-454.

Crawford JH, Wainwright A, Heavens R, Pollock J, Martin DJ, Scott RH, Seabrook GR (2000) Mobilisation of intracellular $\mathrm{Ca}^{2+}$ by mGluR5 metabotropic glutamate receptor activation in neonatal rat cultured dorsal root ganglia neurones. Neuropharmacology 39:621-630.

DeHaven WI, Smyth JT, Boyles RR, Putney JW Jr (2007) Calcium inhibition and calcium potentiation of Orai1, Orai2, and Orai3 calcium releaseactivated calcium channels. J Biol Chem 282:17548-17556.

DeHaven WI, Jones BF, Petranka JG, Smyth JT, Tomita T, Bird GS, Putney JW Jr (2009) TRPC channels function independently of STIM1 and Orail. J Physiol 587:2275-2298.

Devor M, Seltzer Z (1999) Pathology of damaged nerves in relation to chronic pain. In: Textbook of pain, Ed 4 (Wall PD, Melzack R, eds), pp 129-164. Edinburgh: Churchill Livingstone.

Dziadek MA, Johnstone LS (2007) Biochemical properties and cellular localisation of STIM proteins. Cell Calcium 42:123-132.

Emptage NJ, Reid CA, Fine A (2001) Calcium stores in hippocampal synaptic boutons mediate short-term plasticity, store-operated $\mathrm{Ca}^{2+}$ entry, and spontaneous transmitter release. Neuron 29:197-208.

Fuchs A, Lirk P, Stucky C, Abram SE, Hogan QH (2005) Painful nerve injury decreases resting cytosolic calcium concentrations in sensory neurons of rats. Anesthesiology 102:1217-1225.

Fuchs A, Rigaud M, Hogan QH (2007) Painful nerve injury shortens the intracellular $\mathrm{Ca}^{2+}$ signal in axotomized sensory neurons of rats. Anesthesiology 107:106-116.

Galli C, Meucci O, Scorziello A, Werge TM, Calissano P, Schettini G (1995) Apoptosis in cerebellar granule cells is blocked by high $\mathrm{KCl}$, forskolin, and IGF-1 through distinct mechanisms of action: the involvement of intracellular calcium and RNA synthesis. J Neurosci 15:1172-1179.

Gasperini R, Choi-Lundberg D, Thompson MJ, Mitchell CB, Foa L (2009) Homer regulates calcium signalling in growth cone turning. Neural Dev 4:29.

Gemes G, Rigaud M, Weyker PD, Abram SE, Weihrauch D, Poroli M, Zoga V, Hogan QH (2009) Depletion of calcium stores in injured sensory neurons: anatomic and functional correlates. Anesthesiology 111:393-405.

Ghosh A, Greenberg ME (1995) Calcium signaling in neurons: molecular mechanisms and cellular consequences. Science 268:239-247.

Gibson A, Fernandes F, Wallace P, McFadzean I (2001) Selective inhibition of thapsigargin-induced contraction and capacitative calcium entry in mouse anococcygeus by trifluoromethylphenylimidazole (TRIM). Br J Pharmacol 134:233-236. 
Glitsch MD, Bakowski D, Parekh AB (2002) Store-operated $\mathrm{Ca}^{2+}$ entry depends on mitochondrial $\mathrm{Ca}^{2+}$ uptake. EMBO J 21:6744-6754.

Grynkiewicz G, Poenie M, Tsien RY (1985) A new generation of $\mathrm{Ca}^{2+}$ indicators with greatly improved fluorescence properties. J Biol Chem 260:3440-3450.

Guenther S, Reeh PW, Kress M (1999) Rises in $\left[\mathrm{Ca}^{2+}\right]_{\mathrm{i}}$ mediate capsaicinand proton-induced heat sensitization of rat primary nociceptive neurons. Eur J Neurosci 11:3143-3150.

Hanani M (2005) Satellite glial cells in sensory ganglia: from form to function. Brain Res Brain Res Rev 48:457-476.

Handy RL, Wallace P, Gaffen ZA, Whitehead KJ, Moore PK (1995) The antinociceptive effect of 1-(2-trifluoromethylphenyl)imidazole (TRIM), a potent inhibitor of neuronal nitric oxide synthase in vitro, in the mouse. Br J Pharmacol 116:2349-2350.

Herms J, Schneider I, Dewachter I, Caluwaerts N, Kretzschmar H, Van Leuven F (2003) Capacitive calcium entry is directly attenuated by mutant presenilin-1, independent of the expression of the amyloid precursor protein. J Biol Chem 278:2484-2489.

Hofer AM, Fasolato C, Pozzan T (1998) Capacitative $\mathrm{Ca}^{2+}$ entry is closely linked to the filling state of internal $\mathrm{Ca}^{2+}$ stores: a study using simultaneous measurements of $I_{\mathrm{CRAC}}$ and intraluminal $\left[\mathrm{Ca}^{2+}\right]$. J Cell Biol 140:325-334.

Hogan Q, Sapunar D, Modric-Jednacak K, McCallum JB (2004) Detection of neuropathic pain in a rat model of peripheral nerve injury. Anesthesiology 101:476-487.

Hogan Q, Lirk P, Poroli M, Rigaud M, Fuchs A, Fillip P, Ljubkovic M, Gemes G, Sapunar D (2008) Restoration of calcium influx corrects membrane hyperexcitability in injured rat dorsal root ganglion neurons. Anesth Analg 107:1045-1051.

Hoth M, Penner R (1992) Depletion of intracellular calcium stores activates a calcium current in mast cells. Nature 355:353-356.

Hoth M, Penner R (1993) Calcium release-activated calcium current in rat mast cells. J Physiol 465:359-386.

Kawano T, Zoga V, Gemes G, McCallum JB, Wu HE, Pravdic D, Liang MY, Kwok WM, Hogan Q, Sarantopoulos C (2009) Suppressed Ca ${ }^{2+} / \mathrm{CaM} /$ CaMKII-dependent $\mathrm{K}_{\mathrm{ATP}}$ channel activity in primary afferent neurons mediates hyperalgesia after axotomy. Proc Natl Acad Sci U S A 106:8725-8730.

Kawasaki T, Ueyama T, Lange I, Feske S, Saito N (2010) Protein kinase C-induced phosphorylation of Orail regulates the intracellular $\mathrm{Ca}^{2+}$ level via the store-operated $\mathrm{Ca}^{2+}$ channel. J Biol Chem 285:25720-25730.

Kerschbaum HH, Cahalan MD (1998) Monovalent permeability, rectification, and ionic block of store-operated calcium channels in Jurkat T lymphocytes. J Gen Physiol 111:521-537.

Kim SH, Chung JM (1992) An experimental model for peripheral neuropathy produced by segmental spinal nerve ligation in the rat. Pain 50:355-363.

Kim SJ, Song SK, Kim J (2000) Inhibitory effect of nitric oxide on voltagedependent calcium currents in rat dorsal root ganglion cells. Biochem Biophys Res Commun 271:509-514.

Klejman ME, Gruszczynska-Biegala J, Skibinska-Kijek A, Wisniewska MB, Misztal K, Blazejczyk M, Bojarski L, Kuznicki J (2009) Expression of STIM1 in brain and puncta-like co-localization of STIM1 and ORAI1 on depletion of $\mathrm{Ca}^{2+}$ store in neurons. Neurochem Int 54:49-55.

Kojundzic SL, Puljak L, Hogan Q, Sapunar D (2010) Depression of $\mathrm{Ca}^{2+} /$ calmodulin-dependent protein kinase II in dorsal root ganglion neurons after spinal nerve ligation. J Comp Neurol 518:64-74.

Korzeniowski MK, Popovic MA, Szentpetery Z, Varnai P, Stojilkovic SS, Balla T (2009) Dependence of STIM1/Orail-mediated calcium entry on plasma membrane phosphoinositides. J Biol Chem 284:21027-21035.

Kruglikov I, Gryshchenko O, Shutov L, Kostyuk E, Kostyuk P, Voitenko N (2004) Diabetes-induced abnormalities in ER calcium mobilization in primary and secondary nociceptive neurons. Pflugers Arch 448:395-401.

Lee JH, Daud AN, Cribbs LL, Lacerda AE, Pereverzev A, Klöckner U, Schneider T, Perez-Reyes E (1999) Cloning and expression of a novel member of the low voltage-activated T-type calcium channel family. J Neurosci 19:1912-1921.

Lepple-Wienhues A, Cahalan MD (1996) Conductance and permeation of monovalent cations through depletion-activated $\mathrm{Ca}^{2+}$ channels $\left(I_{\text {CRAC }}\right)$ in Jurkat T cells. Biophys J 71:787-794.

Lipscombe D, Kongsamut S, Tsien RW (1989) Alpha-adrenergic inhibition of sympathetic neurotransmitter release mediated by modulation of N-type calcium-channel gating. Nature 340:639-642.

Lirk P, Poroli M, Rigaud M, Fuchs A, Fillip P, Huang CY, Ljubkovic M, Sapunar D, Hogan Q (2008) Modulators of calcium influx regulate membrane excitability in rat dorsal root ganglion neurons. Anesth Analg 107:673-685.

Liu M, Liu MC, Magoulas C, Priestley JV, Willmott NJ (2003) Versatile regulation of cytosolic $\mathrm{Ca}^{2+}$ by vanilloid receptor I in rat dorsal root ganglion neurons. J Biol Chem 278:5462-5472.

Lu SG, Gold MS (2008) Inflammation-induced increase in evoked calcium transients in subpopulations of rat dorsal root ganglion neurons. Neuroscience 153:279-288.

Lu SG, Zhang X, Gold MS (2006) Intracellular calcium regulation among subpopulations of rat dorsal root ganglion neurons. J Physiol 577:169-190.

Machaca K (2003) $\mathrm{Ca}^{2+}$-calmodulin-dependent protein kinase II potentiates store-operated $\mathrm{Ca}^{2+}$ current. J Biol Chem 278:33730-33737.

McElroy SP, Drummond RM, Gurney AM (2009) Regulation of storeoperated $\mathrm{Ca}^{2+}$ entry in pulmonary artery smooth muscle cells. Cell Calcium 46:99-106.

Mercer JC, Dehaven WI, Smyth JT, Wedel B, Boyles RR, Bird GS, Putney JW $\mathrm{Jr}$ (2006) Large store-operated calcium selective currents due to coexpression of Orail or Orai2 with the intracellular calcium sensor, Stim1. J Biol Chem 281:24979-24990.

Moore PK, Babbedge RC, Wallace P, Gaffen ZA, Hart SL (1993) 7-Nitro indazole, an inhibitor of nitric oxide synthase, exhibits anti-nociceptive activity in the mouse without increasing blood pressure. Br J Pharmacol 108:296-297.

Nohmi M, Hua SY, Kuba K (1992) Basal $\mathrm{Ca}^{2+}$ and the oscillation of $\mathrm{Ca}^{2+}$ in caffeine-treated bullfrog sympathetic neurones. J Physiol 450:513-528.

Ong HL, Cheng KT, Liu X, Bandyopadhyay BC, Paria BC, Soboloff J, Pani B, Gwack Y, Srikanth S, Singh BB, Gill D, Ambudkar IS (2007) Dynamic assembly of TRPC1-STIM1-Orail ternary complex is involved in storeoperated calcium influx. Evidence for similarities in store-operated and calcium release-activated calcium channel components. J Biol Chem 282:9105-9116.

Parekh AB (1998) Slow feedback inhibition of calcium release-activated calcium current by calcium entry. J Biol Chem 273:14925-14932.

Park CY, Shcheglovitov A, Dolmetsch R (2010) The CRAC channel activator STIM1 binds and inhibits L-type voltage-gated calcium channels. Science 330:101-105.

Paschen W (2001) Dependence of vital cell function on endoplasmic reticulum calcium levels: implications for the mechanisms underlying neuronal cell injury in different pathological states. Cell Calcium 29:1-11.

Putney JW Jr (2001) Pharmacology of capacitative calcium entry. Mol Interv 1:84-94

Putney JW Jr (2003) Capacitative calcium entry in the nervous system. Cell Calcium 34:339-344.

Putney JW Jr (2007a) New molecular players in capacitative $\mathrm{Ca}^{2+}$ entry. J Cell Sci 120:1959-1965.

Putney JW Jr (2007b) Recent breakthroughs in the molecular mechanism of capacitative calcium entry (with thoughts on how we got here). Cell Calcium 42:103-110.

Renganathan M, Cummins TR, Hormuzdiar WN, Black JA, Waxman SG (2000) Nitric oxide is an autocrine regulator of $\mathrm{Na}^{+}$currents in axotomized C-type DRG neurons. J Neurophysiol 83:2431-2442.

Rigaud M, Gemes G, Weyker PD, Cruikshank JM, Kawano T, Wu HE, Hogan QH (2009) Axotomy depletes intracellular calcium stores in primary sensory neurons. Anesthesiology 111:381-392.

Rychkov G, Brereton HM, Harland ML, Barritt GJ (2001) Plasma membrane $\mathrm{Ca}^{2+}$ release-activated $\mathrm{Ca}^{2+}$ channels with a high selectivity for $\mathrm{Ca}^{2+}$ identified by patch-clamp recording in rat liver cells. Hepatology 33:938-947.

Sapunar D, Ljubkovic M, Lirk P, McCallum JB, Hogan QH (2005) Distinct membrane effects of spinal nerve ligation on injured and adjacent dorsal root ganglion neurons in rats. Anesthesiology 103:360-376.

Schmidt R, Schmelz M, Forster C, Ringkamp M, Torebjörk E, Handwerker H (1995) Novel classes of responsive and unresponsive C nociceptors in human skin. J Neurosci 15:333-341.

Scott BS, Edwards BA (1980) Electric membrane properties of adult mouse DRG neurons and the effect of culture duration. J Neurobiol 11:291-301. Smyth JT, Dehaven WI, Bird GS, Putney JW Jr (2008) $\mathrm{Ca}^{2+}$-store- 
dependent and -independent reversal of Stim1 localization and function. J Cell Sci 121:762-772.

Stathopulos PB, Li GY, Plevin MJ, Ames JB, Ikura M (2006) Stored $\mathrm{Ca}^{2+}$ depletion-induced oligomerization of stromal interaction molecule 1 (STIM1) via the EF-SAM region: an initiation mechanism for capacitive $\mathrm{Ca}^{2+}$ entry. J Biol Chem 281:35855-35862.

Szikra T, Barabas P, Bartoletti TM, Huang W, Akopian A, Thoreson WB, Krizaj D (2009) Calcium homeostasis and cone signaling are regulated by interactions between calcium stores and plasma membrane ion channels. PLoS One 4:e6723.

Thayer SA, Perney TM, Miller RJ (1988) Regulation of calcium homeostasis in sensory neurons by bradykinin. J Neurosci 8:4089-4097.

Tobin V, Gouty LA, Moos FC, Desarménien MG (2006) A store-operated current (SOC) mediates oxytocin autocontrol in the developing rat hypothalamus. Eur J Neurosci 24:400-404.

Tsukamoto A, Kaneko Y (1993) Thapsigargin, a $\mathrm{Ca}^{2+}$-ATPase inhibitor, depletes the intracellular $\mathrm{Ca}^{2+}$ pool and induces apoptosis in human hepatoma cells. Cell Biol Int 17:969-970.

Usachev YM, Thayer SA (1999) $\mathrm{Ca}^{2+}$ influx in resting rat sensory neurones that regulates and is regulated by ryanodine-sensitive $\mathrm{Ca}^{2+}$ stores. J Physiol 519:115-130.

Waddell PJ, Lawson SN (1990) Electrophysiological properties of subpopulations of rat dorsal root ganglion neurons in vitro. Neuroscience 36:811-822.

Wanaverbecq N, Marsh SJ, Al-Qatari M, Brown DA (2003) The plasma membrane calcium-ATPase as a major mechanism for intracellular calcium regulation in neurones from the rat superior cervical ganglion. J Physiol 550:83-101.

Wang Y, Deng X, Mancarella S, Hendron E, Eguchi S, Soboloff J, Tang XD, Gill DL (2010) The calcium store sensor, STIM1, reciprocally controls Orai and CaV1.2 channels. Science 330:105-109.

Wei H, Wei W, Bredesen DE, Perry DC (1998) Bcl-2 protects against apoptosis in neuronal cell line caused by thapsigargin-induced depletion of intracellular calcium stores. J Neurochem 70:2305-2314.

Weick M, Cherkas PS, Härtig W, Pannicke T, Uckermann O, Bringmann A, Tal M, Reichenbach A, Hanani M (2003) P2 receptors in satellite glial cells in trigeminal ganglia of mice. Neuroscience 120:969-977.

Wu HE, Gemes G, Zoga V, Kawano T, Hogan QH (2010) Learned avoidance from noxious mechanical simulation but not threshold Semmes Weinstein filament stimulation after nerve injury in rats. J Pain 11:280-286.

Yoo AS, Cheng I, Chung S, Grenfell TZ, Lee H, Pack-Chung E, Handler M, Shen J, Xia W, Tesco G, Saunders AJ, Ding K, Frosch MP, Tanzi RE, Kim TW (2000) Presenilin-mediated modulation of capacitative calcium entry. Neuron 27:561-572.

Zheng JH, Walters ET, Song XJ (2007) Dissociation of dorsal root ganglion neurons induces hyperexcitability that is maintained by increased responsiveness to cAMP and cGMP. J Neurophysiol 97:15-25.

Zweifach A, Lewis RS (1996) Calcium-dependent potentiation of storeoperated calcium channels in T lymphocytes. J Gen Physiol 107:597-610. 